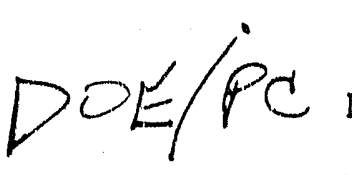

DOE/PC/79924--T3

DE92 019661

\title{
OPERATING CHARACTERISTICS OF ROTATING BEDS
}

\author{
Majjd Keyvani and Nelson C. Gardner \\ Chemical Engineering Department \\ Case Western Reserve University \\ Cleveland, Ohio 44106
}

\section{Technical Progress Report}

prepared for

US Department of Energy

Pittsburgh Energy Technology Center

Pittsburgh, Pennsylvania

DOE \# DE-FG22-87PC 79924

\section{DISCLAIMER}

This report was prepared as an account of work sponsored by an agency of the United States Government. Neither the United States Government nor any agency thereof, nor any of their employees, makes any warranty, express or implied, or assumes any legal liability or responsibility for the accuracy, completeness, or usefulness of any information, apparatus, product, or process disclosed, or represents that its use would not infringe privately owned rights. Reference herein to any specific commercial product, process, or service by trade name, trademark, manufacturer, or otherwise does not necessarily constitute or imply its endorsement, recommendation, of favoring by the United States Government or any agency therenf. The views mendapions of the United States Government or any agency thereot.'

US/DOE Patent Clearance is not required prior to the publication of this document. 


\begin{abstract}
Vapor-liquid contacting in high gravitational fields offers prospects for significant reductions in the physical size, capital, and operating costs of packed towers. Pressure drops, power requirements, mass transfer coefficients and liquid residence time distributions are reported for a rotating bed separator. The beds studied were rigid, foamed aluminum, with specific surface areas ranging from 650 to $3000 \mathrm{~m}^{2} / \mathrm{m}^{2}$. Gravitational fields were varied from 50 to $300 \mathrm{~g}$.
\end{abstract}


TABLE OF CONTENTS

ABSTRACT $\ldots \ldots \ldots \ldots \ldots \ldots \ldots$ p.......

1. INTRODUCTION ................. 1

2. PREVIOUS WORK ................. 2

2.1. Centrifugal Tray Absorber $\ldots \ldots \ldots \ldots \ldots$ 2

2.2. Rotating Packed Bed $\ldots \ldots \ldots \ldots \ldots \ldots$. 2

3. EQUIPMENT AND PROCEDURES ............

3.1. Schematic of the Rotor ............. 4

3.2. Packing $\ldots \ldots \ldots \ldots \ldots \ldots \ldots \ldots$

3.3. Liquid Distributor $\ldots \ldots \ldots \ldots \ldots \ldots$

3.4. $\underline{\text { Rotor Assembly and Seals }} \ldots \ldots \ldots \ldots \ldots$...... 5

3.5. Elow Diagram $\ldots \ldots \ldots \ldots \ldots \ldots \ldots$

3.6. Measurements of Operatjng Parameters .......

3.7. Data Acquisition ............... 6

4. PRESSURE DROP CHARACTERISTICS OF ROTATING BEDS 6

4.1. Theory $\ldots \ldots \ldots \ldots \ldots \ldots \ldots$. 6

4.1.1. Dry Packing..$\ldots \ldots \ldots \ldots \ldots \ldots$. 6

4.1.1.a. Pressure Drop Across the Bed $\ldots \ldots \ldots \ldots$. 6

4.1.1.b. Pressure Drop Between the Housing and Rotor ... 8

4.1.2. Irrigated Packing .............. 10

4.1.2a. Pressure Drop Inside of Rotor $\ldots \ldots \ldots \ldots$

4.1.2b. Pressure Drop Between the Housing and Rotor ... 11

4.2. Experimental Results and Discussion ........ 
4.2.1. Typical Pressure Drop Observation ........ 12

4.2.2. Gravitational Effects $\ldots \ldots \ldots \ldots \ldots$

4.2.3. Gas and Liquid Flow Rate Effects ....... 13

4.2.4 Effect of Packing Speciijc Surface Area ...... 14

4.3. Comparison with Model ............ 14

4.3.1. Zero Flow $\ldots \ldots \ldots \ldots \ldots \ldots \ldots \ldots$

4.3.2. Dry Bed $\ldots \ldots \ldots \ldots \ldots \ldots \ldots \ldots$

4.3.3. Irrigated Bed .............. 15

5. MASS TRANSFER CHARACTERISTICS OF RO IATING BEDS .15

5.1. Theory $\ldots \ldots \ldots \ldots \ldots \ldots \ldots \ldots$

5.2. Experimental Results and Discussion ....... 18

5.2.1. Gravitational Effect $\ldots \ldots \ldots \ldots \ldots \ldots$

5.2.2. Effect of Packing Specific Surface Area ...... 19

5.2.3. Effect of Viscosity ............ $\quad 19$

5.2.4. Comparison with Models ........... 19

6. POWER REQUIREMENT FOR ROTATING BEDS . . . . . . 20

6.1. Theory ................ 20

6.1.1. Bearing Friction $\ldots \ldots \ldots \ldots \ldots \ldots .20$

6.1.2. Windage Effect $\ldots \ldots \ldots \ldots \ldots \ldots$

6.1.3. Liquid Acceleration ........... 22

6.2. Experimental Results and Discussion ........ 22

6.2.1. Bearing Friction $\ldots \ldots \ldots \ldots \ldots \ldots$

6.2.2. Windage Effect $\ldots \ldots \ldots \ldots \ldots \ldots .23$

6.2.3. Liquid Acceleration $\ldots \ldots \ldots \ldots \ldots \ldots$ 
6.2.4. Total Power Consumption .......... 24

7. RESIDENCE TIME DISTRIBUTION .......... 24

7.1. Theory $\ldots \ldots \ldots \ldots \ldots \ldots \ldots \ldots$

7.2. Experimental Results and Discussion ........ 25

8. CONCLUSIONS ............... 26

9. Acknowledgement .............. 27

10. NOMENCLATURE .............. 27

11. REFERENCES ............... 29 


\section{INTRODUCTION:}

Packed towers are mass transfer devices used in various gas-liquid separations. They consist of vertical cylindrical towers filled with suitable sized and shaped packings to enhance mass transfer. The liquid phase, introduced at the top of the column, flows down through the packing. The gas phase is introduced at the bottom of the column and flows countercurrent to the liquid, exiting at the top of tower. Mass transfer occurs at the interface of gas and liquid. Thermodynamics dictates the equilibrium distribution of the molecular species between the two phases, but the actual distribution is limited by mass transfer rates.

Suppose a packed tower is operated in a high gravitational field. The liquid is pulled through the column by the field, and it is now more difficult to flood the column. As a result, higher gas and liquid flowrates can be used, the specific surface area of the packing can be increased, and the liquid films become thinner. High volumetric mass transfer coefficients can then be achieved. These enhanced volumetric mass transfer coefficients enable the physical size of the equipment to be drastically reduced.

High gravitational fields can be achieved by rotating a specially shaped bed in the form of a rigid metal foam in a shape of a disk with a hole in the center. Liquid is sprayed into the center of the bed and flows outward through the bed because of the centrifugal force. The gas is introduced at the outer surface of the packing and is forced inward countercurrently to the liquid by pressure driving forces. The liquid film being pulled through the high surface area packing is thinned, enhancing the volumetric mass transfer coefficients.

This work is concerned broadly with the operating characteristics of rotating beds. The objectives of this work are to 1)characterize and predict the pressure drop in rotating bed, 2) investigate the effect of gravitational acceleration on volumetric mass transfer coefficients, 3 ) determine the residence time distribution of the liquid phase in rotating beds, 4) investigate the required power consumption of rotating beds. 
No prior work has been reported to model the pressure drop characteristics of rotating beds. There is no information available in the literature about residence time distribution and the power consumption of rotating beds. In prior work reported on mass transfer characteristics of rotating packed beds, typical packings such as glass beads, wire mesh, metal sponges, and other industrial packings were used. Here, experiments were performed with one piece, rigid, torus shaped, dimensionally stable, high porosity and high surface area foam metal as packings. To the best of the authors' knowlege, this work presents first set of data for this type of packing.

\section{PREVIOUS WORK:}

\subsection{Centrifugal Tray Absorbers:}

The concept of contacting liquids and vapors in a centrifugal field was reported in early studies of Podbielniak [1,2]. The centrifugal absorber consisted of perforated cylindrical sieve trays for gas-liquid contacting. The perforation were dimpled inward to provide weirs for retaining some of the liquid. The perforations were off-set axially from tray to tray to prevent any direct short circuiting. This device was later improved by Todd $[3,4]$ to provide more effective contacting for the phases, and to increase the stage capacity by utilizing a number of units operating on a vertical shaft. Similar work was reported by Chambers and Walls [5]: their centrifugal absorber consisted of a set of rings attached to the rotating plate to generate climbing liquid films and sprays repeatedly.

\subsection{Rotating Packed Beds:}

Vivian et al [6] studied the effect of gravitational field on gas absorption in a packed column by mounting a cylindrical packet bed on the horizontal arm of a large centrifuge. The gravitational force was varied from 1 to 6.4 times the gravity force. For their system configuration, the liquid phase volumetric mass transfer coefficient varies with the gravitational force to the 0.41 to 0.48 power. 
In the late 1970's, there appeared in the European and U.S. patents literatures a series of patents assigned to Imperial Chemical Industries (ICI London) [7-10], introducing the HIGEE packed bed rotor for absorption and distillation applications. The HIGEE packed bed was operated at mean acceleration fields of 200 to $500 \mathrm{~g}$, and the reported volumetric mass transfer coefficients were up to 100 times larger than the values obtained in conventional packed columns. The reported volumetric mass transfer coefficients varied with the gravitational force to the 0.14 to 0.54 powers. ICI, in spite of extensive tests, published very little information. Glitch Inc. (Dallas), which has acquired worldwide rnarketing rights, also reported a test history of HIGEE with various systems at wide range of process conditions and physical properties [11]. Glitch Inc. already installed a unit two years ago for the U.S. Coast Guard at a facility near Traverse City, Michigan, to air-stripe aviation fuel from contaminated ground water, and field tests are underway for an usitisclosed natural-gas producer in the U.S. [12]. However, no publications are cited in the open literatures about the results of the tests.

Recently, Dudukovic et al reported theoretical and experimental work on rotating packed beds $[13,14,15]$. They reported separately the effect of rotational speed on gas-liquid interfacial area and liquid side mass transfer coefficient to explain the overall enhancement of volumetric mass transfer coefficients in rotating packed beds. Their findings show that the volumetric mass transfer coefficient increases with the rotational speed as a fractional power of .61 to .89 which is in agreement with the data of Vivian et al and within the range estimated by ICI. Their theoretical framework was based on film flow on a rotating blades and rotating disks. Their flooding tests with air-water system showed the Sherwood correlation for the dumped rings is conservative by $40-70 \%$. The bed in this study was $3 \mathrm{~mm}$ glass beads which had a specific surface area of $120 \mathrm{~m}^{2} / \mathrm{m}^{3}$ and a porosity of 0.4 . 
In all the above work, no attempt was made to model the pressure drop characteristics of the rotating packed bed. There is no information available about residence time distribution on rotating packed beds. No work has been reported in the literature on power requirement of rotating packed becis.

\section{EQUIPMENT and PROCEDURE:}

\subsection{Schematic of the Rotor:}

Figure 1 shows a simplified schematic of the rotating bed. The liquid enters from the inner pipe of the stationary double pipe (2), is sprayed by the distributor (1) on the inside edge of the bed, and then is thrown out into the housing (3) by the centrifugal force. The gas enters the stationary housing and flows through the rotating bed; due to the imposed pressure gradient, countercurrent to the liquid. After leaving the bed, the exits through the double pipe (4). The liquid collects in the bottom of the housing wall and forms a liquid seal (5) in a trap.

\subsection{Packings:}

The packing for the rotating bed is a one piece torus-shaped unit (6), made of an aluminum foam metal. It is dimensionally stable in the high gravitational fields. The outside diameter is $45.7 \mathrm{~cm}$, the inside diameter is $25.4 \mathrm{~cm}$, and the thickness is $4.4 \mathrm{~cm}$. Three different beds were studied. The beds specifications are presented in Tablc Our stress analysis indicates the beds can be operated from 600 to $2000 \mathrm{rpm}$, giving a gravitational field of 100 to 1000 times gravity.

\subsection{Liquid Distributor:}

The liquid distributor is a manifold consisting of twelve distributing tubes. The division of the liquid stream into parts by means of this type of manifold is uneven because it is not possible to keep the liquid pressure perfectly constant inside the main channel [16]. However, for the above specifications, the change in the rate of the flow between two 
extreme ports is less than 5\%. This manifold provided adequate liquid distribution and reduced the chance of the liquid entrainment in the inner edge of the rotor where the flooding is most probable, since the centrifugal acceleration is lowest and the gas velocity highest at this point.

\subsection{Rotor Assembly and Seals:}

The rotor assembly is mounted on a $5.1 \mathrm{crn}$ diameter shaft, supported by two bearings, in a cantilevered design. A variable speed $5 \mathrm{hp} \mathrm{AC}$ motor with a belt drives the rotor assembly.

Seals are required in two locations in the rotor assembly: the shaft (7), and the double pipe assembly for the gas exit (8). Inexpensive silicone rubber radial lip seals were used in both locations.

\subsection{Flow Diagram:}

Figure 2 shows the flow diagram of the general experimental apparatus. The feed and recycle pumps can supply up to $45 \mathrm{~kg} / \mathrm{sec}-\mathrm{m}^{2}$ for this packing (30 gpm). The compressor can deliver up to $2.5 \mathrm{~kg} / \mathrm{sec}-\mathrm{m}^{2}$ air for this packing (120 acfm). The air can be heated or enter the rotor at room temperature.

\subsection{Measurements of Operating Parameters:}

Both the liquid and vapor flowrates were determined by measuring the pressure drop across restriction orifices (RO). Differential pressure transducers were used to measure the pressure drop across the orifices. The pressure drops across the bed were measured by placing the probes for the transducers at the inlet and outlet of the rotor as shown in Figure 1.

The torque and rotational speed measurements were made to determine the required power for rotating beds. A sprocke:/pulley torque transducer was connected to the end of the drive shaft to measure the required torque for the rotating bed. A magnetic pick-up tachometer was used to measure the speed of rotation. 
For residence time distribution experiments (RTD), concentrated $\mathrm{NaNO}_{3}$ solutions were prepared and charged to a tracer inlet loop. By a simultaneous half turn of two shut-off valves, the tracer was introduced into the liquid stream inlet. The liquid passes the RTD sensors at the inlet (6) and outlet (7) of the rotor. The electrical conductivity inlet sensor consisted of two $0.158 \mathrm{~cm}$ stainless steel rods (1/16" rods) mounted perpendicularly and 180 degrees apart on the body of a teflon tube. The teflon tube serves as one of the distributing tubes for the liquid distributor. The outlet sensor consisted of two $0.158 \mathrm{~cm}$ stainless steel rods ( $1 / 16^{\prime \prime}$ rods) mounted on a teflon trough which is placed very close to the rotor outlet. The purpose of the trough design is to catch the spray from the rotor.

Carbon dioxide concentrations in the liquid were determined by a specific ion electrode. Carbon dioxide concentration in the gas phase were determined by gas chromatography.

\subsection{Data Acquisition:}

All the flow, pressure, temperature, torque, and rotational speed transducers are interfaced to a computer. The data for the RTD experiments was taken by a digital oscilloscope.

\section{PRESSURE DROP CHARACTERISTICS OF ROTATING BEDS}

\subsection{THEORY}

\subsubsection{Dry Packing:}

The total pressure drop in a rotating bed is the sum of the pressure drop of two regions: the pressure drop between the stationary housing and the spinning rotor, $\Delta \mathrm{P}_{0}$, and the pressure drop across the rotor, $\Delta \mathrm{P}_{\mathrm{i}}$. Each region will be analyzed.

\subsection{1.a Pressure Drop Across the Beal:}

If the pressure drop througa the packed bed is not large, the gas phase can be assumed incompressible. Assuming that the velocity in the axial direction is zero, and the angular 
velocity does not vary in the tangential direction, then the continuity equation in a cylindrical coordinate for the gas phase, at steady state, may be written as:

$$
\frac{1}{\mathrm{r}} \frac{\partial}{\partial \mathrm{r}}(\epsilon \mathrm{rV})=0
$$

Here $\mathrm{V}$ is the velocity in radial direction, $\mathrm{r}$ is the radial distance, and $\epsilon$ is the packing porosity.

A general momentum balance can be written as follows:

$$
\begin{array}{ll}
-\rho_{\mathrm{g}} \mathrm{V} \frac{\mathrm{dV}}{\mathrm{dr}}=\frac{\mathrm{dP}}{\mathrm{dr}}+\rho_{\mathrm{g}} \frac{\mathrm{U}^{2}}{\mathrm{r}}+\frac{\text { Drag For ce }}{\text { unit volume }} & \text { r-direction } \\
-\rho_{\mathrm{g}} \mathrm{V} \frac{\mathrm{dU}}{\mathrm{dr}}=\rho_{\mathrm{g}} \frac{\mathrm{UV}}{\mathrm{r}}+\frac{\text { Drag For ce }}{\text { unit volume }} & \text { o-direction }
\end{array}
$$

Here $U$ is the tangential velocity, $P$ is the pressure, and $\rho_{\mathrm{g}}$ is the gas density.

To further simplify the model, a solid body rotation in the packed bed is considered and the coriolis force is ignored (an assumption that may be verified later). Assuming that the drag force exerted on the unit volume of gas by viscous transfer in the packed bed has the form of Ergun correlation (or similar available models such as the Carman-Kozeny or Morton model), equations (2) and ( 3 , reduce to:

$$
-\rho_{\mathrm{g}} \frac{\overline{\mathrm{V}}}{\epsilon^{2}} \frac{\mathrm{d} \overline{\mathrm{V}}}{\mathrm{d} \mathrm{r}}=-\frac{\mathrm{dP}}{\mathrm{d} \overline{\mathrm{r}}}+\rho_{\mathrm{g}} \omega^{2} \mathrm{r}+\rho_{\mathrm{g}} \mathrm{A} \overline{\mathrm{V}}+\rho_{\mathrm{g}} \mathrm{B} \overline{\mathrm{V}}^{2}
$$

Here $\bar{V}$ is the local superfacial gas velocity, related to interstitial gas velocity by $\bar{V}=V \epsilon$. $\omega$ is the rotation speed, and $A$ and $B$ are correlation coefficients and depend on gas physical properties and packing specifications as follows: 
For Ergun's model: $A=150(1-\epsilon) \mu_{g} / \epsilon^{3}\left(\varphi_{g} d_{p}\right)^{2}, B=1.75(1-\epsilon) \rho_{g} / \epsilon^{2} \varphi_{g} d_{p}$

For Morton's model: $A=8.5 \mu_{g} a_{p} / \epsilon^{3}, B=a_{p} \rho_{g}(R e)^{-1 /} / \epsilon^{3}$

Here $a_{p}$ is the specific surface area of the packing, $d_{p}$ is the packing diameter, $\varphi_{k}$ is the sphericity of the packing particles, and Re is the gas Reynold's number based on the specific surface area. In general, these models are writiten in terms of the slip velocity of the two phases. However, since the superfacial solid velocity is zero, unly the gas velocity appears in the equation (we will see later that this is not the case when the packed bed is irrigated by liquid).

Equation (4) may be integrated across the entire bed to obtain the pressure drop inside of the rotor, $\Delta \mathrm{P}_{\mathrm{i}}$, for a dry bed.

\subsection{1b Pressure Drop Between the Housing and Rotcr:}

Outside of the rotor, we have a flow situation similar to flow between two disks, one spinning and one stationary, with the inflow. There have been numerous studies of this type of flow in the literature [17-21]. The basic flow configuration is als follows: the rotating disk imparts rotation to the fluid, leading to a distribution of angular velocity from the rotating disk value at the disk to zero at the stationary housing wall. The drag forces act on the fluid in the direction of rotation at the rotating disk and in the opposite direction at the wall surface. The pressure gradient is generated centrifugally in the gap between the disk and the wall, and its value depends on the effective average angular velocity of the flow field. The pressure tends to be a function of radius only and independent of axial position in the gap. The angular velocity of the fluid near the rotating disk is above the effective averaze, and hence the fluid near the rotating disk is thrown radiaily outward. On the other hand, fluid close to the stationary housing has smaller angular velocity than the effertive average so that it flows radially inward. The effect of inflow due to leakage (in the rotating packed 
bed the leakage is the total gas flow rate) is to increase the radia! pressure gradient. This increase in pressure gradient can be explained in terms of the rotation effect of inflow. The fluid tends to rotate faster due to inflow and so generates a larger pressure gradient.

A momentum integral method is used in analyze the pressure gradient between the rotating disk and the stationary housing. The governing equations are the same as equations (1) to (3). The difference is that the simplifica'ion made in evaluating $A P_{1}$, ignoring the coriolis force and and the assumption of solid body rotation, are not valid here. A distribution of tangential velocity exists which can be obidined by solving equation (3). The drag forces are the radiai and tangential friction stresses on the wall and the rotating disk. Ergun's or Morton's models may no longer be used for this case. These forces are deduced frim work performed by Von. F. Shultz-Grunow [20] and are defined as follows:

$$
\begin{aligned}
& \tau_{\mathrm{rw}}=\text { stress in radial direction at wall }=f_{\mathrm{r}} \rho_{\mathrm{g}} \frac{\mathrm{U}^{2}}{2} \\
& \tau_{\mathrm{rd}}=\text { stress in radial direction at rotating disk }=f_{\mathrm{r}} \rho_{\mathrm{g}} \frac{(\mathrm{r} \omega-\mathrm{U})^{2}}{2} \\
& \tau_{\mathrm{tw}}=\text { stress in tangential direction at wall } \mathrm{g} f_{\mathrm{\varepsilon}} \rho_{\mathrm{g}} \frac{\mathrm{U}^{2}}{2} \\
& \tau_{\mathrm{td}}=\text { stress in tangential direction at rotating disk= } f_{\mathrm{t}} \rho_{\mathrm{g}} \frac{(\mathrm{r} \omega-\mathrm{U})^{2}}{2}
\end{aligned}
$$

where $f_{\mathrm{r}}$ and $f_{\mathrm{t}}$ are the friction coefficients that take the following expressions for the turbulent flow:

$$
\begin{aligned}
& f_{r}=\frac{0.0391}{\left(\rho_{g} \omega r_{0}^{2} / \mu_{g}\right)^{0.2}} \times \frac{1}{\left(1-r / r_{0}\right)^{0.4}} \\
& f_{t}=\frac{0.0996}{\left(\rho_{g} \omega r_{0}^{2} / \mu_{g}\right)^{0.2}} \times \frac{1}{\left(1-r / r_{0}\right)^{0.4}}
\end{aligned}
$$


Here $\mu_{\mathrm{g}}$ is the gas viscosity, and $\mathrm{r}_{\mathrm{o}}$ is the disk outside radius. After substituting for $\mathrm{f}_{\mathrm{r}}$ and $f_{t}$ from equations (5) and (6), equations (2) and (3) can be solved simultaneously to evaluate the pressure gradient in the gap between the rotating disk and the stationary wall, $\Delta \mathrm{P}_{0}$. The equations were solved numerically and a $4^{\text {th }}$ order Runge-Kutta method was employed to approximate the integrations.

\subsubsection{Irrigated Packing:}

\subsubsection{Pressure Drop Inside of Rotor:}

To extend the model for dry packing to the irrigated parking equation (4) will be modified to account for the liquid presence. The velocity terms related to Ergun formula will be written in terms of the slip velocity of the gas and liquid phases:

$$
\frac{d P}{d r}=A\left(\nabla-V_{i}\right)+B\left(\nabla-V_{i}\right)^{2}+\rho_{g} \omega^{2} r+\rho_{g} \frac{d V}{d r}
$$

Here $V_{i}$ is the interfacial velocity.

The equation of motion for the liquid steam, assuming laminar and fully developed flow within the short distance that both phases are brought into contact, may be written as follows:

$$
\mu_{1} \frac{d^{2} V_{1}}{d z^{2}}=-\frac{d P}{d r}+\rho_{1} \omega^{2} r
$$

Here $V_{1}$ is the liquid phase velocity, $\mu_{1}$ is the liquid viscosity, $\rho_{1}$ is the liquid density, and $z$ is the distance in direction perpendicular to the radial direction. The above equation can be solved based on the boundary conditions:

$$
\begin{aligned}
& v_{1}=v_{i} @ z=\delta \\
& v_{1}=0 @ z=0
\end{aligned}
$$


$\delta$ is the liquid film thickness. The solution, after integrating over the liquid film thickness, may be written in term of the liquid flowrate as follows:

$$
Q=\left(\rho_{1} \omega^{2} \mathrm{r}-\frac{\mathrm{dP}}{\mathrm{d} \tau}\right) \frac{\mathrm{h} \delta^{3}}{12 \mu_{1}}+\frac{\mathrm{hV} \mathrm{i}_{\mathrm{i}} \delta}{2}
$$

where $Q$ is the liquid flowrate, and $h$ is the axial height of the packing.

Equations (7) and (9) are coupled through $\mathrm{dP} / \mathrm{dr}, \mathrm{V}_{\mathrm{i}}$, and $\delta$ terms (unknowns).

Therefore, one more equation is needed to solve for the above unknowns, and that arises from the boundary condition indicating equal stresses at the gas and liquid interface:

$$
\tau_{g}=\tau_{1} @ z=\delta
$$

Here $\tau_{\mathrm{g}}$ and $\tau_{1}$ are the gas and liquid shear stresses respectively.

Solving the equations by using the above boundary condition is excessively involved and complicated. Instcad, we try to estimate the liquid film thickness by using either the asymptotic solution for liquid film on a rotating disk [13] or the liquid film flow on an inclined surface [22] after substituting centrifugal acceleration for the gravity

For given film thicknes, "gas and liquid flowrates, speed of the rotation, and liquid and gas physical nroperties, equations (7) and (9) can be solved simultaneously to evaluate the pressure drop across the rotating bed. The Runge Kutta method order of 4 was employed to solve the equations numerically.

\subsection{2b. Pressure Drop Between the Housing and Rotor:}

The above analysis for the irrigated packing gives the pressure drop across the bed. It is assumed that the pressure drop between the the rotating disk and the stationary housing is 
not affected by the presence of the liquid; therefore, the same analysis as dry packing is applied for the irrigated packing for the outside of the rotor.

\subsection{EXPERDMENTAL RESULTS \& DISCUSSIONS:}

\subsubsection{Typical Pressure Drop Observation:}

A peculiar phenomenon is observed in pressure drop measurements of rotating beds. Figure 3 shows a typical plot of pressure drop against time. When the rotor is stationary and the gas is turned on, the pressure drop is $11 \mathrm{~Pa} / \mathrm{cm}$ of packing. When the rotor is turned on, the pressure drop increases to $50 \mathrm{~Pa} / \mathrm{cm}$ of packing. When the liquid is turned on, countercurrent to the gas flow, the pressure drop decreases by more than a factor of 2 , to 22 $\mathrm{Pa} / \mathrm{cm}$ of packing. For this experiment, a gas flowrate of $1.0 \mathrm{~kg} / \mathrm{sec}-\mathrm{m}^{2}$ and a liquid flowrate of $36 \mathrm{~kg} / \mathrm{sec}-\mathrm{m}^{2}$ were used. Packing surface area was $1476 \mathrm{~m}^{2} / \mathrm{m}^{3}$, and the packed bed was rotating at $600 \mathrm{rpm}$.

To understand this phenomenon, various experiments were performed to isolate the influence of different operating parameters.

\subsubsection{Gravitational Effects (Constant Liquid and Gas Flow):}

Experiments were carried out to measure the pressure drop at various accelerations (varying speed of rutalion). The liquid and gas flowrates were held constant at $36 \mathrm{~kg} / \mathrm{sec} \mathrm{m}^{2}$ and 1 $\mathrm{kg} / \mathrm{sec} \mathrm{m}^{2}$, respectively. The packing with the specific surface area of $1476 \mathrm{~m}^{2} / \mathrm{m}^{3}$ was used.

The pressure drops were measured for the following situations: i) zero flow (gas off-liquid off), ii) liquid off-gas on, iii) liquid on-gas off, and iv) liquid on-gas on. These data are plotted in Figure 4.

At zero flow a radial pressure gradient develops because of the rotation of the air both inside the rotor and between the rotor, and the stationary housing. This is associated with the pressure required to overcome the centrifugal head due to the rotation. The pressure drop increases when the gas is turned on (gas on-liquid off). This increase results mainly 
from the drag (frictional pressure drop) and inertia effects. The pressure drops for case of liquid-on gas-off are almost the same as those of liquid-off gas-off case, indicating that liquid has little effect on pressure drop for gas-off situations. However, a decrease in the pressure drop is observed in case of liquid-on gas-on as compared with liquid-off gas-on case. This is not a typical trend observed in conventional packed towers. In conventional towers the irrigated bed shows a higher pressure drop than that of dry bed.

The solid lines in Figure 4 are the second power fit for the experimental data. This indicates the dependency of the pressure drop on rotational speed is $\Delta \mathrm{P} \propto \omega^{2}$ at constant liquid and gas flowrates, as suggested in the proposed model.

\subsubsection{Gas and Liquid Flowrate Effects:}

Pressure drop vs. gas flowrates curves were obtained at constant liquid flowrate and speed of rotation. Gas flowrates ranged from $0.1 \mathrm{~kg} / \mathrm{sec}-\mathrm{m}^{2}$ to $1.95 \mathrm{~kg} / \mathrm{sec}-\mathrm{m}^{2}$. Corresponding semi-log representation of the results (as suggested by Teutsch [23]) has two advantages: i) lines for constant pressure and liquid flowrate are practically straight, ii) flooding points can be clearly identified. Figure 5 shows a typical result for $12 \mathrm{~kg} / \mathrm{sec}-\mathrm{m}^{2}$ and $36 \mathrm{~kg} / \mathrm{sec}-\mathrm{m}^{2}$ liquid flowrates at $600 \mathrm{rpm}$ with the $1476 \mathrm{~m}^{2} / \mathrm{m}^{3}$ packing. However, the flooding points, the breakpoint in the plots where the pressure drop increases rapidly, was not reached. Liquid entrainment in the region of the distributor was encountered at the points indicated. The fact that the distributing tubes of the distributor are not placed as close as possible to the inner surface of the packing may cause the excessive entrainment of the liquid before the flooding (the liquid is not accelerated since it does not reach the bed). To confirm that the same pressure drop characteristics are observed at different acceleration fields, a liquid flowrate was selected $\left(36 \mathrm{~kg} / \mathrm{sec}-\mathrm{m}^{2}\right)$, and the total pressure drop was measured at varying gas flowrates for the rotational spe $3 \mathrm{ds}$ of $600,840,1200 \mathrm{rpm}$ to give a gravitational acceleration of 50,100, and 200g, respectively, (based on inner radius of the rotor). Figure 6 shows the results. Obviously, a higher pressure drop is observed, at 
constant liquid and gas flowrates, for higher speed of rotation (the centrifugal force contribution to the total pressure drop). It is very clear that the curve corresponding to 1200 rpm is not even near flooding (no entrainment was observed at full capacity liquid and gas flowrates).

Typical pressure drop versus liquid flowrate data are shown in Figure 7.

\subsubsection{Effect of Packing Specific Surface Area:}

To investigate the effects of packing surface area, tests were made with different surface area packings. The packings have a specific surface area of 656, 1476, and 2952 $\mathrm{m}^{2} / \mathrm{m}^{3}$, all with 0.92 void fraction. The pressure drops were measured for dry and wet beds at rotational speeds of 600 and $900 \mathrm{rpm}$. The results are shown in Figure 8. The higher pressure drops are associated with the higher surface area packing for the dry and wet beds.

\subsection{Comparison with Model:}

\subsubsection{Zero Flow:}

With no gas and liquid flowing, the pressure drops were measured at varying rotational speeds. The experimental results are compared with the values estimated by the proposed model. Figure 9 shows this comparison.

\subsubsection{Dry Bed:}

The experimentally obtained values of the pressure drop, for dry packing, are compared with the values estimated by the proposed model in Figure 10. A.ll of the predictions are within $\pm 20 \%$ error shown by the two broken lines in Figure 10 . The experimental data was taken as the gas flowrates were varied from 0.163 to $1.31 \mathrm{~kg} / \mathrm{sec}-\mathrm{m}^{2}$, while the speed of rotation was ranging from 600 to $1200 \mathrm{rpm}$. Packing surface areas of 1476 and $2952 \mathrm{~m}^{2} / \mathrm{m}^{3}$ were used. 


\subsubsection{Irrigated Bed:}

The experimentally obtained values of the total pressure drop, for irrigated packing, are compared with the values estimated by the model proposed for the wet packing in Figure 11.. The operating conditions were similar to those of the dry packing experiments, however, the liquid flowrates were varied from 9 to $36 \mathrm{~kg} / \mathrm{sec}-\mathrm{m}^{2}$. The agreement between the calculated values and the experimental data is satiasfactory (within $\pm 20 \%$ error). Although, the agreement between the experimental data and the proposed model for the wet packing is promising, but it still does not explain the lower pressure drop for the wet bed (compared to the dry bed). One possible speculation is that the liquid film exposed to the centrifugal field gets thin and behaves like a lubricant film, lowering the drag against the gas phase. Other plausible explanation is a shorter path length for the gas in the wet bed compared to the dry bed. This could also result a decrease in the pressure drop.

The overall experimental results of pressure drop indicates the characteristics of a rotating packed bed are different from those of a conventional packed bed. Therefore, the conventional analysis and their known hydrodynamic relations of packed towers may not be easily applied to rotating packed beds.

\section{MASS TRANSFER CHARACTERISTICS}

\subsection{Theory:}

The total height of a packed column is given by:

$$
\mathrm{H}=(\mathrm{NTU}) \times(\mathrm{HTU})
$$

where 
$H=$ tower height $=r_{0}-r_{i}$

NTU = number of transfer units $=\int_{x_{0}}^{x_{i}} \frac{d x}{x-x_{e}}$

HTU = height of a transfer unit

Here, $r_{0}$ and $r_{i}$ are the outside and inside radii of the rotor, $x_{i}$ is concentration in the rotor inlet, $x_{0}$ is concentration in the rotor outlet, and $x_{e}=$ liquid concentration in equilibrium with bulk gas concentration.

For a given tower height and known concentrations, HTU may be evaluated by equation (10).

The HTU may also be estimated theoretically using equation (11), if the volumetric mass transfer coefficient, $k_{1} a_{e}$, is known:

$$
\mathrm{HTU}=\mathrm{L} / \rho \mathrm{k}_{1} \mathrm{a}_{\mathrm{e}}
$$

Here, $L$ is the liquid superficial flowrate, $\rho$ is the liquid density, $k_{1}$ is the mass transfer coeffient, and $a_{e}$ is the gas-liquid interfacial surface area.

Among theories proposed to describe the liquid mass transfer behavior in a packed column under conventional operation, the penetration theory appears most consistent with the picture existing in a packed tower. Penetration theory suggests that as the liquid flows over each piece of packing in laminar flow, it is completely mixed in passing from one packing piece to the next. Absorption is considered to take place during a series of brief contacts between the liquid and gas in which the dissolved gas diffuses only a short distance into the liquid film. The penetration theory analysis results in the following correlation for $k_{1}$, the liquid side mass transfer coefficient:

$$
\frac{\mathrm{k}_{1} \mathrm{Z}}{\mathscr{D}}=0.918\left(\mathrm{a}_{\mathrm{p}} / \mathrm{a}_{\mathrm{e}}\right)^{1 / 3} \mathrm{Sc}^{1 / 2} \mathrm{Re}^{1 / 3} \mathrm{Gr}^{1 / 6}
$$


where,

$$
\begin{gathered}
\mathrm{Sc}=\mathrm{Schmidt} \text { number }=\mu / \rho \mathscr{D} \\
\mathrm{Re}=\text { Reynolds number }=\mathrm{L} / \mathrm{a}_{\mathrm{p}} \mu \\
\mathrm{Gr}=\text { Grashof number }=\mathrm{Z}^{3} \rho^{2} \mathrm{~g} / \mu^{2}
\end{gathered}
$$

Here, $\mathscr{D}$ is the solute diffusion coefficient in the liquid phase, $\mathrm{L}$ is the superfacial liquid mass flowrate, $\mathrm{Z}$ is the packing height, and $\mu$ is the liquid viscosity.

The liquid side mass transfer coefficient, $k_{1}$, may be evaluated using equation (12), after the effective gas-liquid contacting efficiency, $a_{e} / a_{p}$, is estimated. Among several formulae proposed to correlate interfacial areas, the most general one seems to be the equation by Onda et al [24] that predicts the wetted surface area and not only takes into account surface tension and the surface energy of the packing, but also has a gravity term built in the correlation:

$$
a_{e} / a_{p}=a_{w} / a_{p}=1-\exp \left\{-1.45\left(\sigma_{c} / \bar{\sigma}\right)^{0.75} \operatorname{Re}^{0.1} \mathrm{Fr}^{-0.05} \mathrm{We}^{0.2}\right\}
$$

where,

$a_{w}=$ wetted surface area of the packing

$\bar{\sigma}=$ surface tension of liquid

$\sigma_{\mathrm{c}}=$ critical surface tension of packing material

$\mathrm{Fr}=$ Fraude number $=\mathrm{L}^{2} \mathrm{a}_{\mathrm{p}} / \rho^{2} \mathrm{~g}$

We $=$ Weber number $=L^{2} / \rho \bar{\sigma} a_{p}$

Equation (12) combined with equation (13) may be used to evaluate liquid side volumetric mass transfer coefficient in rotating packed bed by replacing gravitational acceleration, $g$, with rotational acceleration, $a_{r}=\omega^{2} r_{i}$, liquid flowrate per unit width with 
liquid flowrate per perimeter. The major assumption is that the interfacial surface area of the gas-liquid, $a_{e}$, is the same as the packing wetted area, $a_{w}$. Then, equation (11) will be used to estimate the value of height of a transfer unit, HTU.

This is a very simple picture of what could be happening in rotating beds; complications such as actual flow pattern of the fluids, Coriolis force, fluid distribution, and packing shape are all neglected. On the other hand, this approach may provide some tools to reveal some of the significant differences between the rotating beds and conventional packed towers.

\subsection{EXPERIMENTAL RESULTS AND DISCUSSION:}

Experiments were performed to investigate the effects of operating parameters, particularly the acceleration field, the packing specific surface area, and the liquid and gas loading, on HTU. About 75 experimental runs were made at varying operating conditions. The results of the mean values of HTU with the standard error of the mean are summarized in Table 4.

\subsubsection{Gravitational Effects:}

Experimental runs were made with the liquid and gas flowrates held constant at 36 and $1.0 \mathrm{~kg} / \mathrm{sec}-\mathrm{m}^{2}$ respectively, while the rotor speed of rotation was set at $600,850,1130$, and $1385 \mathrm{rpm}$ to achieve centrifugal accelerations of $50,100,182$, and $272 \mathrm{~g}$, respectively (based on the inner radius of the rotor). All three beds were used. Figure 12 shows the influence of the acceleration field on HTU which reflects the dependency of HTU on g, varies from -0.30 to -0.40 , within the range estimated by Dukukovic et al $[14,15]$ and Vivian et al $[6]$. Comparing the slopes of the lines for different packing surface areas suggests that the dependency of HTU on acceleration field is more pronounced at higher surface area packings. 


\subsubsection{Effect of Packing Specific Surface Area:}

The contribution of packing specific surface area on enhanced volumetric mass transfer coefficients is shown in Figure 13. The liquid and gas flowrates for all the experimental rurs in Figure 13 were set at $36 \mathrm{~kg} / \mathrm{sec}-\mathrm{m}^{2}$ and $1.0 \mathrm{~kg} / \mathrm{sec}-\mathrm{m}^{2}$, respectively, while the rotational speeds were set at $600,850,1130$, and $1385 \mathrm{rpm}$ to achieve a centrifugal acceleration of 50 , $100,182,272 \mathrm{~g}$, respectively (based on the inner radius of the rotor). The measured volumetric mass transfer coefficients of $2952 \mathrm{~m}^{2} / \mathrm{m}^{3}$, in all different accelerations, are greater than corresponding values for $1476 \mathrm{~m}^{2} / \mathrm{m}^{3}$, indicating that an increase in specific surface area of the packing will result in higher volumetric mass transfer coefficient. However, as can 1 . seen in Figure 13, the results for $656 \mathrm{~m}^{2} / \mathrm{m}^{3}$ packing do not show the same trend. The volumetric mass transfer coefficients in case of $656 \mathrm{~m}^{2} / \mathrm{m}^{3}$ packing are slightly greater than those of $1476 \mathrm{~m}^{2} / \mathrm{m}^{3}$ packing. This discrepancy, in part, may be 7 ttributed to end effect: that fact the mass transfer cannot be confined to the packing alone. Some mass transsfer may take place as the fine droplets leave the rotor and travel to the housing.

\subsubsection{Effect of Viscosity:}

Increasing the liquid viscosity decreases mass transfer rate due to reduced diffusivity and mixing in the liquid phase. To investigate the effect of viscosity on mass transfer in rotating beds,a solvent-hexane-air system was studied, where the hexane was air stripped from the solvent at $70^{\circ} \mathrm{C}$ and $1 \mathrm{~atm}$. The solvent viscosity was $3 \mathrm{cp}$ at $70^{\circ} \mathrm{C}$.

At rotational speeds of 700 to $1100 \mathrm{rpm}$, HTU's ranges from 1.5-2.5 cm were achieved. The gas and liquid flowrates were $1.0 \mathrm{~kg} / \mathrm{sec}-\mathrm{m}^{2}$ and $36 \mathrm{~kg} / \mathrm{sec}-\mathrm{m}^{2}$ respectively, and the packing with specific surface area of $1476 \mathrm{~m}^{2} / \mathrm{m}^{3}$ was used.

\subsubsection{Comparison with Models:}

The experimentally obtained values of HTU from ail the performed experiments at varying gravitational fields, as well as different packing surface areas, and varying gas and 
liquid flowrates, are compared with the HTU values estinated using equations (11) to (13). The results are presented in Table 5. This comparison is illustrated in Figure 14. Figure 1.4 shows the results with \pm 20 error bar (the broken lines). It is interesting to observe that the estimated values agree fairly well with the experimental values, except for the $656 \mathrm{~m}^{2} / \mathrm{m}^{3}$ packing.

\section{Power Requirement for Rotating Beds}

\subsection{THEORY:}

The power connsumption arises from three main sources: 1) the power required for the acceleration of the liquid to the tip speed of the rotor; 2) the power consumed in overcoming the frictional windage drag of the rotor; and 3 ) the power required for the bearing friction. In addition, there is small power requirement associated with the flow of the vapor between the rotating disk and the stationary housing, and the flow of vapor through the rotor bed.

\subsubsection{Bcaring Friction:}

The power consumed by the bearing friction will be strongly dependent upon the type of the hearing being used. It is reasonable to assume that the frictional loss of benting is directly proportional to speed of rotation. The proportionality may be evaluated experimentally.

\subsubsection{Windage Effect:}

Windage losses may be estimated by considering the flow between two disks, one spinning and one stationary. There have been numerous studies of this type of flow in the literature [17-21]. In particular, the flow pattern of disk in a housing with large gap between 
them (width of the gap compared with the radius of the disk) was investigated for the laminar and for the turbulent flow by Von F. Shultz-Grunow [20]. It was suggested that for large gaps, an additional boundary layer will be formed on the stationar,' housing, as well as on the rotating disk. The fluid in the boundary layer on the revolving disk is centrifuged outwards and this is compensated by a flow inwards in the boundary layer on the stationary housing. For the turbulent flow case, the tangential velocity was assumed to obey the $1 / 7$ th power law. The expressions for the torque, both for the laminar and turbulent cases, are as follows:

$$
\begin{gathered}
\mathrm{T}=2.67 \rho_{\mathrm{g}} \omega^{2} \mathrm{R}^{5}(\mathrm{Re})^{-1 / 2} \quad \text { Laminar } \\
\mathrm{T}=0.0622 \rho_{\mathrm{g}} \omega^{2} \mathrm{R}^{5}(\mathrm{Re})^{-1 / 5} \quad \text { Turbulent }
\end{gathered}
$$

Here, $\mathrm{T}$ is the torque, $\rho_{\mathrm{g}}$ is the gas density, $\mathrm{R}$ is the disk radius, and Re is Reynold's number defined as:

$$
\operatorname{Re}=\rho_{\mathrm{g}} \omega \mathrm{R}^{2} / \mu_{\mathrm{g}}
$$

where $\mu_{\mathrm{g}}$ is the gas viscosity.

The power is of course the product of the torque and angular velocity:

$$
\text { Power }=\mathrm{T} \times \omega
$$




\subsubsection{Liquid Acceleration:}

The largest contributor to power consumption is the acceleration of the liquid to the top speed of the rotor. The theoretical power required to bring the liquid to angular velocity of the rotor may be calculated as follows:

$$
\text { Power }=\text { Change in Kinetic Energy }=(\text { K.E. })_{\text {out }}-(\text { K.E. })_{\text {in }}
$$

Assuming that the liquid enter the rotor with no angular velocity, (K.E.) $)_{\text {in }}=0$, the power may be estimated ds:

$$
\text { Power }=(K . E .)_{\text {out }}=I \omega^{2} / 2
$$

Here, $I$ is the moment of inertia $=m r_{\text {out }}^{2}$, where $m$ is the liquicl flowrate, and $r_{\text {out }}$ is the outside radius of the rotor. $\omega$ is the angular velocity of the rotor and is equal to $2 \pi \mathrm{N}$, where $\mathrm{N}$ is the rotational speed.

\subsection{Experimental Results and Discussion:}

Figure 15 shows the total power consumption as a function of liquid Dowrate at three different accelerations.

In order to sort out the factors contributing to the power consumption, experiments were performed to isolate the contributors. 


\subsubsection{Bearing Friction:}

To isolate the bearing contribution of nower consumption, the rotor was dismantled from the shaft, and the power was measured as the shaft was allowed to rotate in the open housing. Figure 16 presents the results. It can be seen that it is reasonable to assume that the bearing frictional loss is directly proportional to rotational speed, Power $=0 . c(\mathrm{rpm})$, for our equipment.

\subsubsection{Windage Effects:}

To investigate the windage effects, the power measurements were made at varying acceleration fields (varying speed of rotation) with the liquid and gas flows off. The bearing power consumption was subtrac'ted out. The experimentally obtained values of the power were compared with the values estimated by equations (20) and (21) proposed by Von. F. Shultz-Grunow [20]. The model predicts extremely low values for the windage effects compared with the experimental values (order of magnitude less at low speeds). The model predicts the windage loss varies with the cube of rotational speed. Howevere, Figure 16 shows a $3 / 2$ power dependency of power consumption on speed, Power $=8.79 \times 10^{-3}(\mathrm{rpm})^{1 \cdot 5}$. One of the factors for the low prediction may come from the mismatch of the apparatus setup. Shultz-Grunow's disk was free within housin, while in our setup the rotor is engaged to a lip seal, which in turn, tends to increase the power consumption due to frictional loss.

\subsubsection{Liquid Acceleration:}

Experiments were carried out to measure the power at varying rotational speeds at three different liquid flowrates, $1.40,1.0$, and 0.65 liter/sec, and zero gas flowrate. The bearing an windage power consumption were subtracted out. Figure 17 shows the results. 


\subsubsection{Total Power Consumption:}

Based on the results of all the components contributing to the power consumption, the total power may be written as:

$$
\text { Total Power }=a \omega^{2}+b \omega^{\mu \cdot 5}+c \omega
$$

where $a, b$, and $c$ are constants. The total power was calculated from the empirical equation derived for the bearing and windage effects, and the theoretical power required for the liquid acceleration ( change in kinetic energy $=1 \omega^{2} / 2$ ). The calculated values are compared with the experimentally obtained values in Figure 18. The difference between the calculated and experimental values is the result of loss of energy, conversion of mechanical energy to heat. Note also that a reduction in total power consumption is obtained when the gas flows through the rotor.

\section{Residence Time Distribution Characteristics}

\subsection{THEORY:}

Residence time distribution (RTD) an.Jysis has been a valuable tool in obtaining information on the fluid motion and mixing in a continuous flow system $[25,26]$. The experimental technique is a stimulus-response technique. The stimulus is a tracer input into the fluid entering the vessel, whereas the response is a time record of the tracer leaving the vessel. A perfect tracer has exactly the same flow properties as the substance it represents, yet it is sufficiently different in some nonflow attribute that it can be detected by an analytical instrument. In aqueous systems the choice usually falls on electrolytes. The following mathematical expressions are widely used in tracer work to characterize the data: 


$$
\begin{gathered}
\bar{t}=\left(\int_{0}^{\infty} t C(t) d t\right) /\left(\int_{0}^{\infty} C(t) d t\right) \\
\sigma^{2}=\left(\int_{0}^{\infty} t^{2} C(t) d t\right) /\left(\int_{0}^{\infty} C(t) d t\right)-\bar{t}^{2}
\end{gathered}
$$

Here, $t$ is the time, $\bar{t}$ is the mean value or the centroid of the distribution, $\sigma$ represents the spread of the distribution, and $\mathrm{C}(\mathrm{t})$ is the tracer concentration. The convolution properties may be used to calculate the mean residence time and the variance of the rotating beds:

$$
\begin{aligned}
& \bar{t}_{\text {bed }}=\bar{t}_{\text {outlet }}-\bar{t}_{\text {inlet }} \\
& \sigma_{\text {bed }}^{2}=\sigma_{\text {outlet }}^{2}-\sigma_{\text {inlet }}^{2}
\end{aligned}
$$

\subsection{EXPERIMENTAL RESULTS AND DISCUSSION:}

Typical stimulus-response curves for a rotating bed is shown in Figure19. The output trace is noisier than the input, which is not surprising given that the output electrode has a trough shape and collects only a thin non-uniform liquid film thickness. The data was smoothed, and the mean residence time was calculated from equations (23) and (25).

Figure 20, and 21 show the dependency of mean residence time on rotational speed and liquid flowrate respectively. As expected the mean residence time decreases as the rotational speed increases or the liquid flowrate increases. The mean residence time varied from 0.4 to 1.8 seconds. 
More tests were performed to investigate the effects of the gas flow on liquid residence time distribution. The preliminary results show that, statistically, the flowrate does not have significant effects on the distribution. Howevere, the output response tend to be narrower in case of the gas flow-on, indicating shorter residence time. More work is underway to study this effect.

\section{CONCLUSIONS:}

In spite of some similar trends in pressure drop characteristics between a rotating packed bed and a conventional packed tower, the experimental results of the pressure drop indicate that they are some substantial differences in hydrodynamics behavior of gas-liquid in these two devices.

The total pressure drop is the sum of the pressure drop inside of the rotor and the pressure drop outside the rotor (between the rotor and the stationary housing). In this study, up to $10 \%$ of the total pressure drop is contributed by the pressure drop outside of the rotor. The agreement between the calculated values and experimental data for the pressure drop was within $\pm 20 \%$ error.

The experimentally measured height of a transfer unit decreases with the gravitational field with 0.35 power. This means that the volumetric mass transfer coefficient should rise with 0.7 power. This finding is in agreement with the data of Vivian et al [6] and within the range estimated by Dudukovic et al [14,15]. The height of a transfer unit, HTU, is found to be 13 to 30 times smaller in rotating packed bed, as compared with that of conventional towers over the same range of liquid mass velocity.

The predicted values of HTU, using the penetration theory modified for rotating packed beds, showed a reasonable agreement with the experimentally obtained values of HTU at varying operating conditions.

The largest contributor to power consumption is the acceleration of the liquid to the top speed of the rôtỗ. The puwer consumption due to the bearing friction is proportional 
with the rotational speed. The introduction of the gas reduces the overall power required for rotating beds.

A mean residence times on order of 0.4 to 2 seconds were obtained for the rotating bed as the rotational speeds were varied from 400 to $1200 \mathrm{rpm}$. The mean residence time decreases as the speed of rotation is increased, or the liquid flowrate is increased.

\section{Acknowledgement:}

This work was supported in part by the Department of Energy, grant no. DE-FG22-79924, and the Chemical Process Product Division of Norton Company.

10. NOMENCLATURE

\begin{tabular}{|c|c|}
\hline$a_{e}$ & effective gas-liquid interfacial area $\left(\mathrm{cm}^{2} / \mathrm{cm}^{3}\right)$ \\
\hline$a_{p}$ & packing specific surface area $\left(\mathrm{cm}^{2} / \mathrm{cm}^{3}\right)$ \\
\hline$a_{r}$ & rotational acceleration $\left(\mathrm{cm} / \mathrm{sec}^{2}\right)$ \\
\hline$a_{w}$ & wetted surface area $\left(\mathrm{cm}^{2} / \mathrm{cm}^{3}\right)$ \\
\hline A & coefficient for Ergun's or Morton's model \\
\hline B & coefficient for Ergun's or Morton's model \\
\hline C & liquid concentration (moles $/ \mathrm{cm}^{3}$ ) \\
\hline $\mathrm{C}_{0}$ & interfacial concentration (moles $/ \mathrm{cm}^{3}$ ) \\
\hline$d_{p}$ & packing diameter $(\mathrm{cm})$ \\
\hline $\mathscr{D}$ & diffusion coefficient $\left(\mathrm{cm}^{2} / \mathrm{sec}\right)$ \\
\hline$f_{r}$ & friction factor in radial direction \\
\hline$f_{t}$ & friction factor in tangential direction \\
\hline $\mathrm{g}$ & gravitational constant $\left(\mathrm{cm} / \mathrm{sec}^{2}\right)$ \\
\hline
\end{tabular}




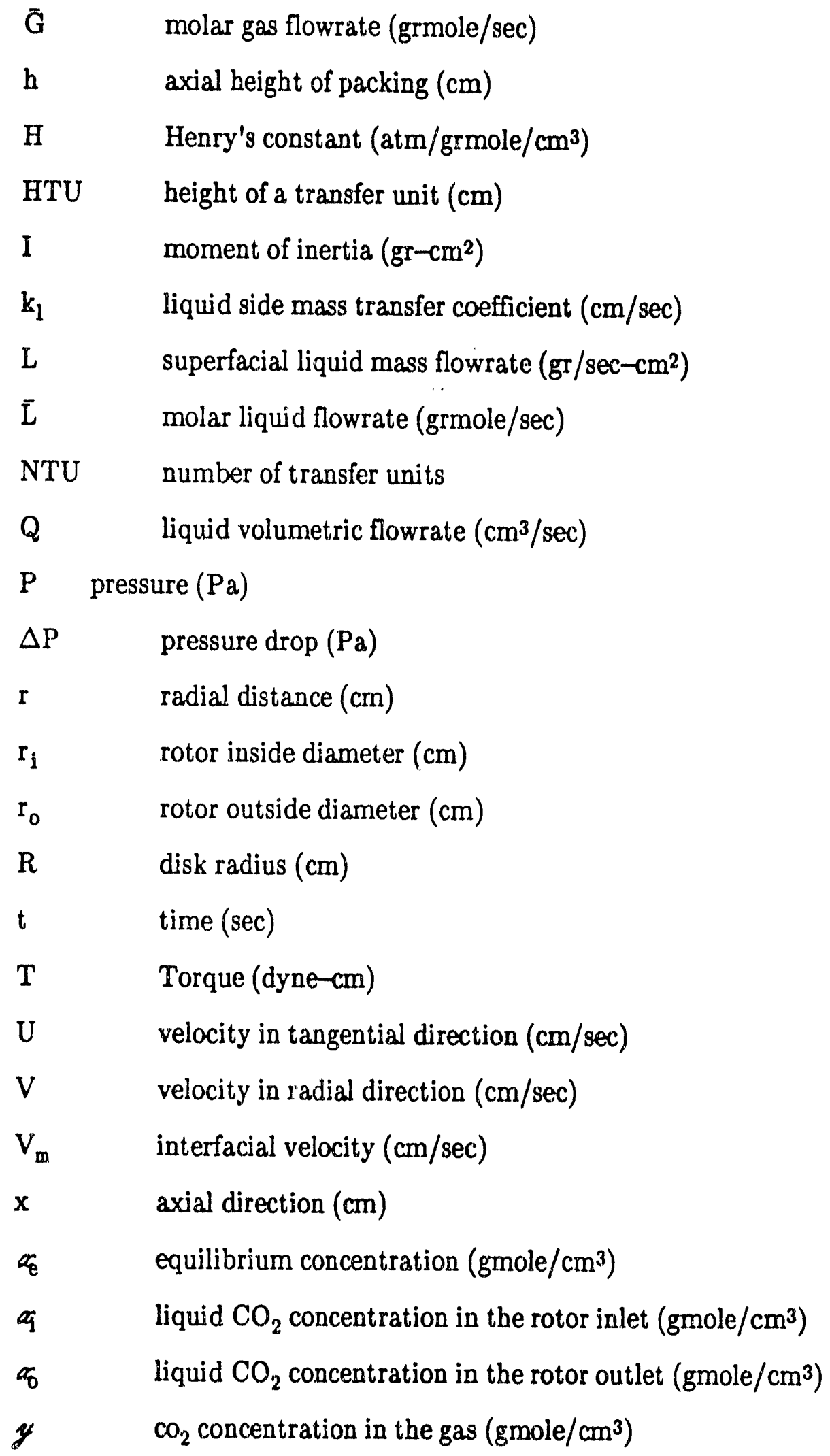


$36 \mathrm{co}_{2}$ concentration in the gas inlet $\left(\mathrm{gmole} / \mathrm{cm}^{3}\right)$

$\mathrm{Z} \quad$ characteristic size of the packing $(\mathrm{cm})$

Greek Notations:

$\epsilon$ packing void fraction

$\varphi_{6} \quad$ packing particle sphericity

$\rho$ liquid density $\left(\mathrm{g} / \mathrm{cm}^{3}\right)$

$\rho_{\mathrm{g}} \quad$ gas density $\left(\mathrm{g} / \mathrm{cm}^{3}\right)$

$\mu_{1} \quad$ liquid viscosity $(\mathrm{g} / \mathrm{cm} \mathrm{sec})$

$\mu_{\mathrm{g}} \quad$ gas viscosity $(\mathrm{g} / \mathrm{cm} \mathrm{sec})$

$\tau \quad$ shear stress $(\mathrm{Pa})$

$\omega \quad$ rotational speed (rpm)

$\sigma \quad$ square root of the variance of the distribution

$\bar{\sigma} \quad$ liquid surface tension (dyne/cm)

$\sigma_{c} \quad$ critical surface tension of packing (dyne $/ \mathrm{cm}$ )

$\delta \quad$ liquid film thickness $(\mathrm{cm})$

Dimensionless Groups:

Fr Fraude number $=L^{2} a_{p} / \rho^{2} g$

Gr Grashof number $=Z^{3} \rho^{2} \mathrm{~g} / \mu^{2}$

Re Reynolds number $=L / a_{\mathrm{p}} \mu$

$\mathrm{Re}_{1} \quad$ Reynolds number $=2 \pi \mathrm{L} / \mu \mathrm{a}_{\mathrm{e}}$

Sc $\quad$ Schmidt number $=\mu / \rho \mathscr{D}$

We Weber number $=L^{2} / \rho \bar{\sigma} a_{p}$

\section{REFERENCES}

1. Podbielniak, W.J., "Continuous Centrifugal Vapor-Liquid Contactor", U.S. Patent 3,233,880 (1966).

2. Podbielniak, W.J., "Continuous Centrifugal Deodorizer" Patent, 3,336,015 (1967). 
3. Todd, D.B., "Multistage Vapor-Liquid Contacting", U.S. Patent , 3,486,743 (1969).

4. Todd, D.B., and D.C. Maclean, "Centrifugal Vapor-Liquid Contacting", British Chemical Engineering, vol. 14, (11) p.1565, (1969).

5. Chambers, H.H., R.C. Walls, Trans. Instn. Chem. Engrs., 32, p.596, (1954).

6. Vivian, J.E., P.L.T. Brian, and V.J. Krudonis, "The Influence of Gravitational Force on Gas Absorption in a Packed Column", AIChE J., 11, 1088 (1965).

7. Ramshaw, C., and R.H. Mallinson, "Mass Transfer Process", U.S. Patent $4,283,255(1981)$.

8. Ramshaw, C., "HIGEE Distillation- An Example of Procesis Intensification", The Chemical Engineer, pp.13-14, Feb. 1983.

9. Wen, J.W., "Centrifugal Gas-Liquid Contact Apparatus", U.S. Patent $4,382,045$ (1983).

10. Wen, J.W., "Centrifugal Gas-Liquid Contact Apparatus", U.S. Patent $4,382,900$ (1983).

11. Mohr, R.J., "The Role of HIGEE Technology in Gas Processing", Report of GPA meeting in Dallas, (1985).

12. Basta, N., "Facelift for Distillation", Chem. Eng., 14-16, March 2, 1987.

13. Munjal S., M.P. Dudukovic, and P. Ramachandran, "Mass Transfer in Rotating Packed Beds. Part I: Development of Gas-Liquid-Solid Mass Transfer Correlations", Submitted for publication to Chemical Enginetring Science (1987).

14. Munjal S., M.P. Dudukovic, and P. Ramachandran, "Mass Transfer in Rotating Packed Beds. Part II: Experimental Results and Comparison with Thory and Gravity Flow", Submitted for publication to Chemical Engineering Science (1987).

15. Munjal, S., M.P. Dudukovic, and P. Ramachandran, "Mass Transfer in a Rotating Packed Bed with Countercurrent Gas-Liquid Flow", Presented at the annual AIChE meeting in Chicago, November 10-15, (1985).

16. Acrivos, A, B.D. Babcock, and R.L. Pigford, Chem. Eng. Sci., 10, 112-124 (1959).

17. Reshotko, E., and U. Rohatgi, "Analysis of Laminar Flow Between Stationary and Rotating Disks with Inflow", NASA Report \# CR-2356 (1974). 
18. Cooper, P., "Turbulent Boundary Layer on a Rotating Disk Calculated with an Effective Viscosity", AIAA Journal, vol. 9, No. 2, p. 255, Feb. 1971.

19. Jimbo, H., "Investigation of the Interaction of Windage and Leakage Phenomena in a Centrifugal Compressor, A.S.M.E., Paper number 56-A47.

20. Schultz-Grumow, F., Der Reibungwiderstand Rotierender Scheiben in Gehausen, Z. Angew. Math. Mech., 15, 191-204 (1935).

21. Reshotko, E., and R.L. Rosenthal, "Laminar Flow Between Two Infinite Disks, One Rotating and the other Stationary", Israel Journal of Technology, vol.9, p. 93, March 1971.

22. Bird, R.B., W.E. Stewart, and E.N. Lightfoot, "Transport Phenomena", John Wiley \& Sons, New York, p.37, p.537, (1960).

23. Teutsch, T., Chem-Ing_Tech, 36, No. 5, pp 496-503, (1964)

24. Onda, K., H. Takeuchi, and Y. Koyama, "Effect of Packing Materials on the Wetted Surface Area", Chem. Eng. Japan, 31, 126-34 (1967).

25. Himmelliau, D.M., K.B. Bischoff, "Process Analysis and Simulation", Chp. 4, Wiley: New York, 1974.

26. Seinfled, J.H., L. Lapidas, "Mathematical Methods in Chemical Engineering", Vol. 3, Prentice-Hall: Englewood Cliffs, New Jersey, 1974. 
TABLE 2. RESULTS OF PRESSIRE DROP AT VARYING ROTATIONAL SPEED

\begin{tabular}{|c|c|c|}
\hline $\begin{array}{l}\text { State of Experimental } \\
\text { Conditions }\end{array}$ & $\begin{array}{c}\text { Speed of Rotation } \\
(\mathrm{rpm})\end{array}$ & $\begin{array}{l}\text { Pressure Drop } \\
(\mathrm{Pa} / \mathrm{cm})\end{array}$ \\
\hline $\begin{array}{l}\text { LIQUTD OFF } \\
\text { GAS OFF }\end{array}$ & $\begin{array}{r}400 \\
600 \\
679 \\
797 \\
853 \\
944 \\
1025 \\
1182 \\
1253\end{array}$ & $\begin{array}{l}10.3 \\
17.0 \\
22.1 \\
29.4 \\
34.8 \\
42.3 \\
49.2 \\
64.6 \\
72.0\end{array}$ \\
\hline $\begin{array}{l}\text { LIQUTD OFF } \\
\text { GAS ON } \\
\quad\left(1.0 \mathrm{~kg} / \mathrm{sec} \mathrm{m}^{2}\right)\end{array}$ & $\begin{array}{r}400 \\
600 \\
681 \\
790 \\
855 \\
947 \\
1047 \\
1136 \\
1203\end{array}$ & $\begin{array}{r}50.9 \\
69.5 \\
86.2 \\
109.9 \\
127.3 \\
147.4 \\
174.1 \\
189.3 \\
221.1\end{array}$ \\
\hline $\begin{array}{l}\text { LIQUID ON } \\
\left(36 \mathrm{~kg} / \mathrm{sec} \mathrm{m}^{2}\right) \\
\text { GAS OFF }\end{array}$ & $\begin{array}{r}400 \\
600 \\
652 \\
740 \\
830 \\
937 \\
1039 \\
1159 \\
1269\end{array}$ & $\begin{array}{r}9.9 \\
16.7 \\
17.4 \\
19.6 \\
26.6 \\
35.8 \\
45.8 \\
54.1 \\
65.5\end{array}$ \\
\hline $\begin{array}{l}\text { LrQUTD ON } \\
\left(36 \mathrm{~kg} / \mathrm{sec}^{2}\right) \\
\text { GAS ON } \\
\left(1.0 \mathrm{~kg} / \mathrm{sec} \mathrm{m}^{2}\right)\end{array}$ & $\begin{array}{r}400 \\
600 \\
700 \\
840 \\
950 \\
1200\end{array}$ & $\begin{array}{r}19.5 \\
30.0 \\
39.9 \\
51.0 \\
74.5 \\
124.0\end{array}$ \\
\hline
\end{tabular}


TABLE 3. COMPARISON OF MEASURED AND CALCULATED PRESSURE DROPS AT VARYING EXPERIMENTAL CONDITIONS FOR THE DRY BED

\begin{tabular}{|c|c|c|c|c|}
\hline $\begin{array}{c}\mathrm{a}_{\mathrm{p}} \\
\left(\mathrm{m}^{2} / \mathrm{m}^{3}\right)\end{array}$ & $\begin{array}{c}\text { Speed of Rotation } \\
(\mathrm{rpm})\end{array}$ & $\begin{array}{c}\text { Gas Flow } \\
\left(\mathrm{kg} / \mathrm{s}-\mathrm{m}^{2}\right)\end{array}$ & $\begin{array}{c}\Delta \mathrm{P}_{\text {measured }} \\
(\mathrm{Pa} / \mathrm{cm})\end{array}$ & $\begin{array}{c}\Delta \mathrm{P}_{\text {calculated }} \\
(\mathrm{Pa} / \mathrm{cm})\end{array}$ \\
\hline \hline 2952 & 600 & $2.9 \times 10^{-2}$ & 68.4 & 73.2 \\
2952 & 695 & $2.9 \times 10^{-2}$ & 81.9 & 79.0 \\
2952 & 766 & $2.9 \times 10^{-2}$ & 91.2 & 81.9 \\
2952 & 840 & $2.9 \times 10^{-2}$ & 111.8 & 86.7 \\
2952 & 917 & $2.9 \times 10^{-2}$ & 127.2 & 95.4 \\
2952 & 600 & $8.7 \times 10^{-3}$ & 27.0 & 24.1 \\
2952 & 600 & $1.4 \times 10^{-2}$ & 32.8 & 32.8 \\
2952 & 600 & $1.5 \times 10^{-2}$ & 34.7 & 33.7 \\
2952 & 600 & $1.7 \times 10^{-2}$ & 45.3 & 40.5 \\
2952 & 600 & $2.0 \times 10^{-2}$ & 48.2 & 47.2 \\
2952 & 600 & $2.5 \times 10^{-2}$ & 49.2 & 55.9 \\
2952 & 600 & $2.8 \times 10^{-2}$ & 55.9 & 60.7 \\
2952 & 600 & $3.0 \times 10^{-2}$ & 61.7 & 73.3 \\
\hline 1476 & 600 & $3.0 \times 10^{-2}$ & 55.9 & 55.9 \\
1476 & 681 & $3.0 \times 10^{-2}$ & 65.5 & 59.8 \\
1476 & 790 & $3.0 \times 10^{-2}$ & 82.9 & 66.5 \\
1476 & 855 & $3.0 \times 10^{-2}$ & 96.4 & 68.4 \\
1476 & 947 & $3.0 \times 10^{-2}$ & 111.8 & 73.3 \\
1476 & 1040 & $3.0 \times 10^{-2}$ & 132.1 & 80.1 \\
1476 & 1140 & $3.0 \times 10^{-2}$ & 151.3 & 86.0 \\
1476 & 1200 & $3.0 \times 10^{-2}$ & 167.7 & 95.0 \\
\hline 656 & 600 & $2.0 \times 10^{-2}$ & 21.2 & 19.3 \\
656 & 600 & $2.5 \times 10^{-2}$ & 23.1 & 21.2 \\
656 & 600 & $3.0 \times 10^{-2}$ & 29.9 & 28.9 \\
\hline
\end{tabular}


TABLE 4. IEIGIT OF TRANSFER UNIT AT VARYING OPERATING CONDITIONS

\begin{tabular}{|c|c|c|c|c|c|}
\hline $\begin{array}{c}\text { Liquid Flow } \\
\left(\mathrm{kg} / \mathrm{sec}-\mathrm{m}^{2}\right)\end{array}$ & $\begin{array}{c}\text { Gas Flow } \\
\left(\mathrm{kg} / \mathrm{sec}-\mathrm{m}^{2}\right)\end{array}$ & $\# \mathrm{~g}$ & $\begin{array}{c}\mathrm{a}_{\mathrm{p}} \\
\left(\mathrm{m}^{2} / \mathrm{m}^{3}\right)\end{array}$ & $\begin{array}{c}\text { HTU } \\
(\mathrm{cm})\end{array}$ & $\begin{array}{c}\text { Standard } \\
\text { Error of Mean }\end{array}$ \\
\hline 18 & 1.0 & 50 & 1476 & 3.0 & 0.052 \\
36 & 1.0 & 50 & 1476 & 3.75 & 0.020 \\
36 & 1.0 & 50 & 2952 & 2.42 & 0.076 \\
36 & 1.0 & 50 & 656 & 2.74 & 0.019 \\
36 & 0.66 & 50 & 1476 & 2.63 & 0.088 \\
\hline 18 & 1.0 & 100 & 1476 & 2.24 & 0.051 \\
36 & 1.0 & 100 & 1476 & 2.94 & 0.177 \\
36 & 1.0 & 100 & 2952 & 1.97 & 0.038 \\
36 & 1.0 & 100 & 656 & 2.20 & 0.000 \\
36 & 0.66 & 100 & 1476 & 2.10 & 0.052 \\
\hline 18 & 1.0 & 182 & 1476 & 1.97 & 0.012 \\
36 & 1.0 & 182 & 1476 & 2.45 & 0.132 \\
36 & 1.0 & 182 & 2952 & 1.67 & 0.014 \\
36 & 1.0 & 182 & 656 & 2.10 & 0.050 \\
36 & 0.66 & 182 & 1476 & 1.92 & 0.020 \\
\hline 18 & 1.0 & 272 & 1476 & 1.79 & 0.003 \\
36 & 1.0 & 272 & 1476 & 2.0 & 0.000 \\
36 & 1.0 & 272 & 2952 & 1.30 & 0.095 \\
36 & 1.0 & 272 & 656 & 1.92 & 0.085 \\
36 & 0.66 & 272 & 1476 & 1.62 & 0.030 \\
\hline
\end{tabular}


TABLE 5. COMPARISON OF IEASURED AND CALCULATED VALUES OF HTU

\begin{tabular}{|c|c|c|}
\hline$\# g^{\prime} s$ & Measured HTU $(\mathrm{cm})$ & $\begin{array}{l}\text { Calculated HTU }(\mathrm{cm}) \\
\text { Using Penetration Theory }\end{array}$ \\
\hline \multicolumn{3}{|c|}{ LIQUTD FLOW: $36 \mathrm{~kg} / \mathrm{s}-\mathrm{m}^{2}$, GAS FLOH: $1.0 \mathrm{~kg} / \mathrm{s}-\mathrm{m}^{2}, \mathrm{a}_{\mathrm{p}}: 14761 /$} \\
\hline $\begin{array}{r}50 \\
100 \\
182 \\
272\end{array}$ & $\begin{array}{l}3.67 \\
2.80 \\
2.30 \\
2.00\end{array}$ & $\begin{array}{l}3.29 \\
2.92 \\
2.50 \\
2.40\end{array}$ \\
\hline \multicolumn{3}{|c|}{ LIQUTD FLOH: $18 \mathrm{~kg} / \mathrm{s}-\mathrm{m}^{2}$, GAS FLOH: $1.0 \mathrm{~kg} / \mathrm{s}-\mathrm{m}^{2}, a_{\mathrm{p}}: 1476 \mathrm{1} / \mathrm{m}$} \\
\hline $\begin{array}{r}50 \\
100 \\
182 \\
272\end{array}$ & $\begin{array}{l}2.98 \\
2.25 \\
1.98 \\
1.79\end{array}$ & $\begin{array}{l}2.50 \\
2.19 \\
1.92 \\
1.83\end{array}$ \\
\hline \multicolumn{3}{|c|}{ LIQUTD FLOW: $36 \mathrm{~kg} / \mathrm{s}-\mathrm{m}^{2}$, GAS FLOH: $1.0 \mathrm{~kg} / \mathrm{s}-\mathrm{m}^{2}, \mathrm{a}_{\mathrm{p}}: 29521 / \mathrm{n}$} \\
\hline & $\begin{array}{l}2.22 \\
1.83 \\
1.67 \\
1.22\end{array}$ & $\begin{array}{l}1.58 \\
1.41 \\
1.22 \\
1.16\end{array}$ \\
\hline \multicolumn{3}{|c|}{ LIQUTD FLOH: $36 \mathrm{~kg} / \mathrm{s}-\mathrm{m}^{2}$, GAS FLOH: $1.0 \mathrm{~kg} / \mathrm{s}-\mathrm{m}^{2}, a_{\mathrm{p}}: 6561 / \mathrm{m}$} \\
\hline & $\begin{array}{l}2.80 \\
2.19 \\
1.98\end{array}$ & $\begin{array}{l}7.90 \\
7.00 \\
6.00\end{array}$ \\
\hline
\end{tabular}




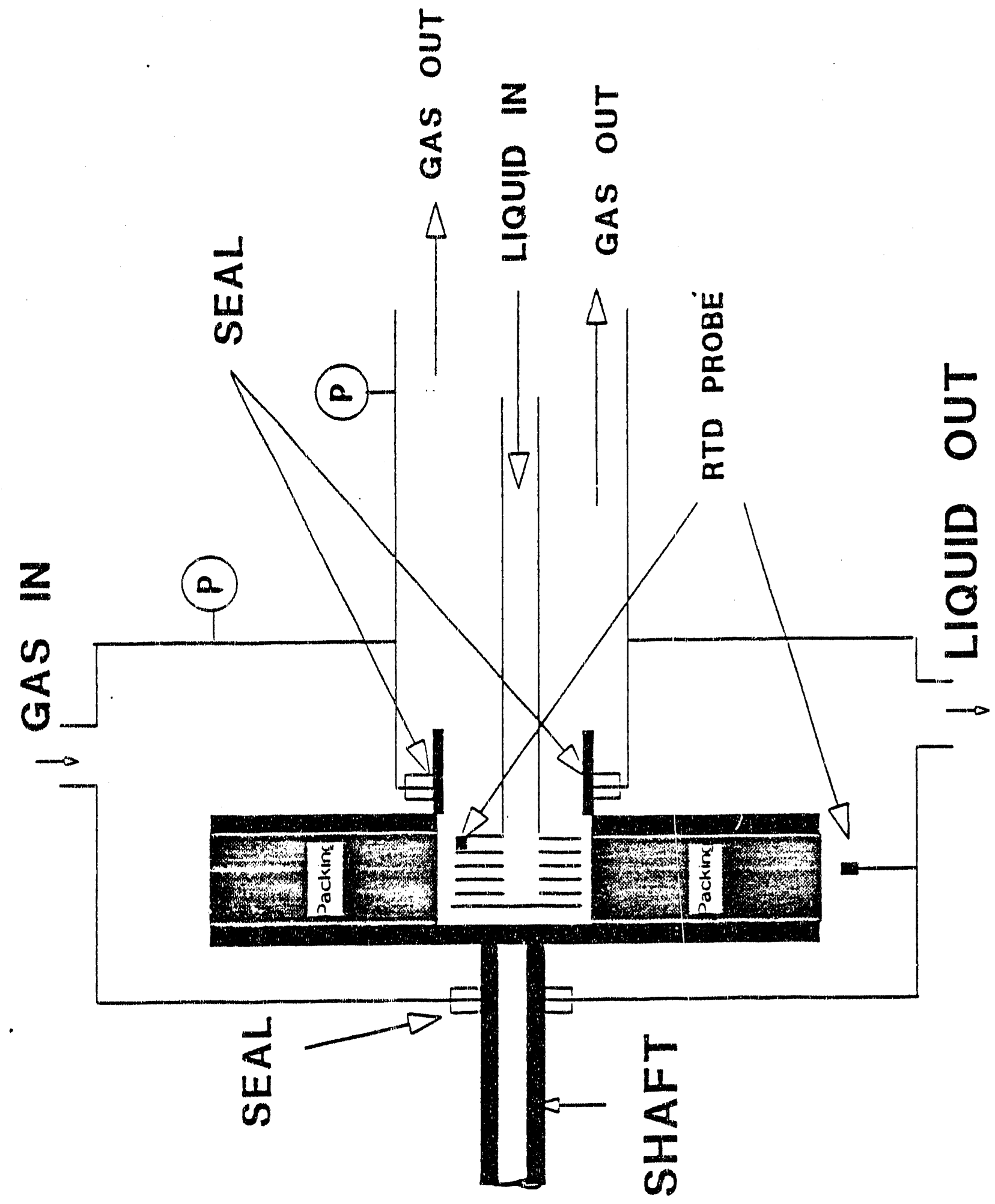

Figure 1. Schematic of Rotating Bed 


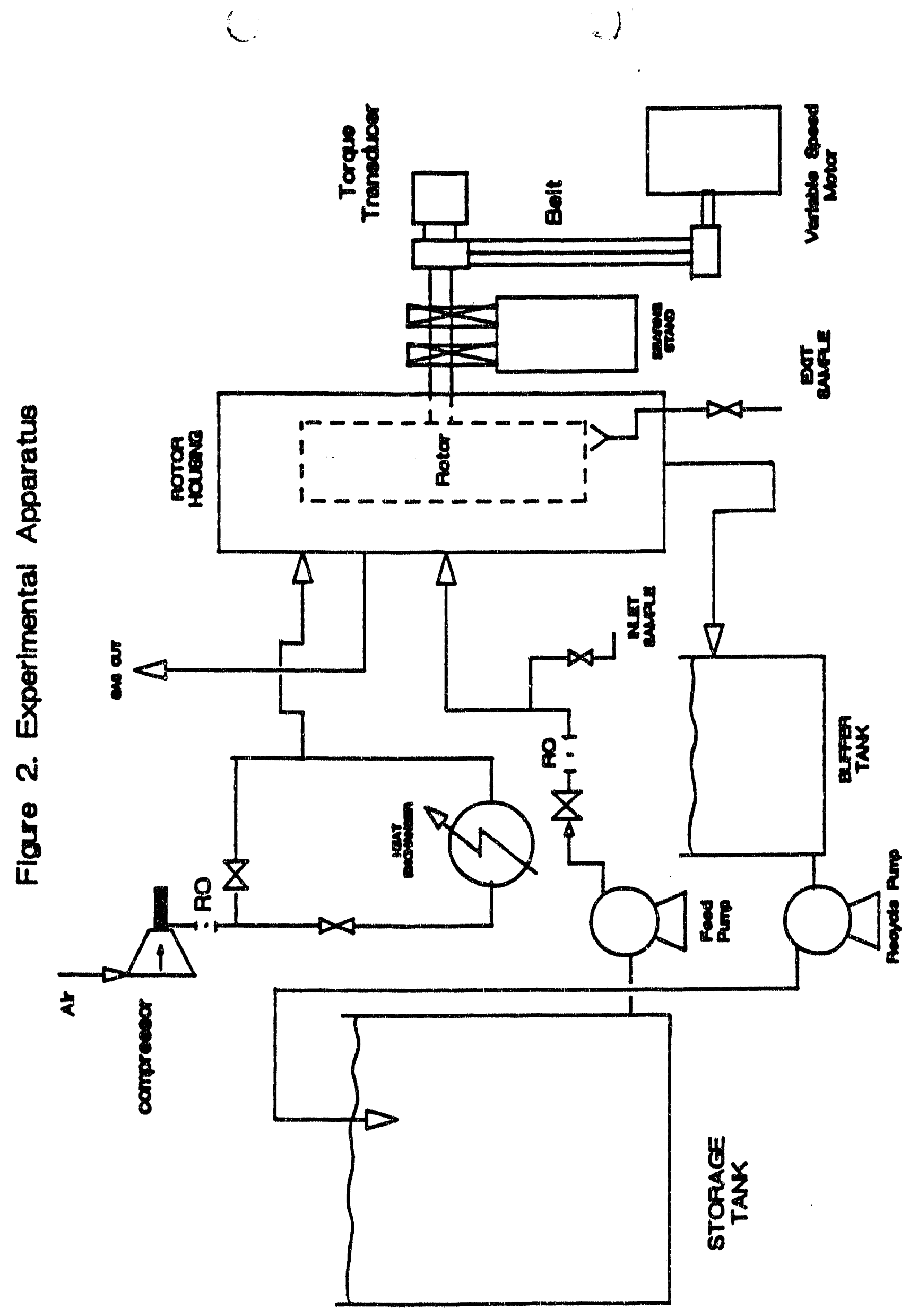



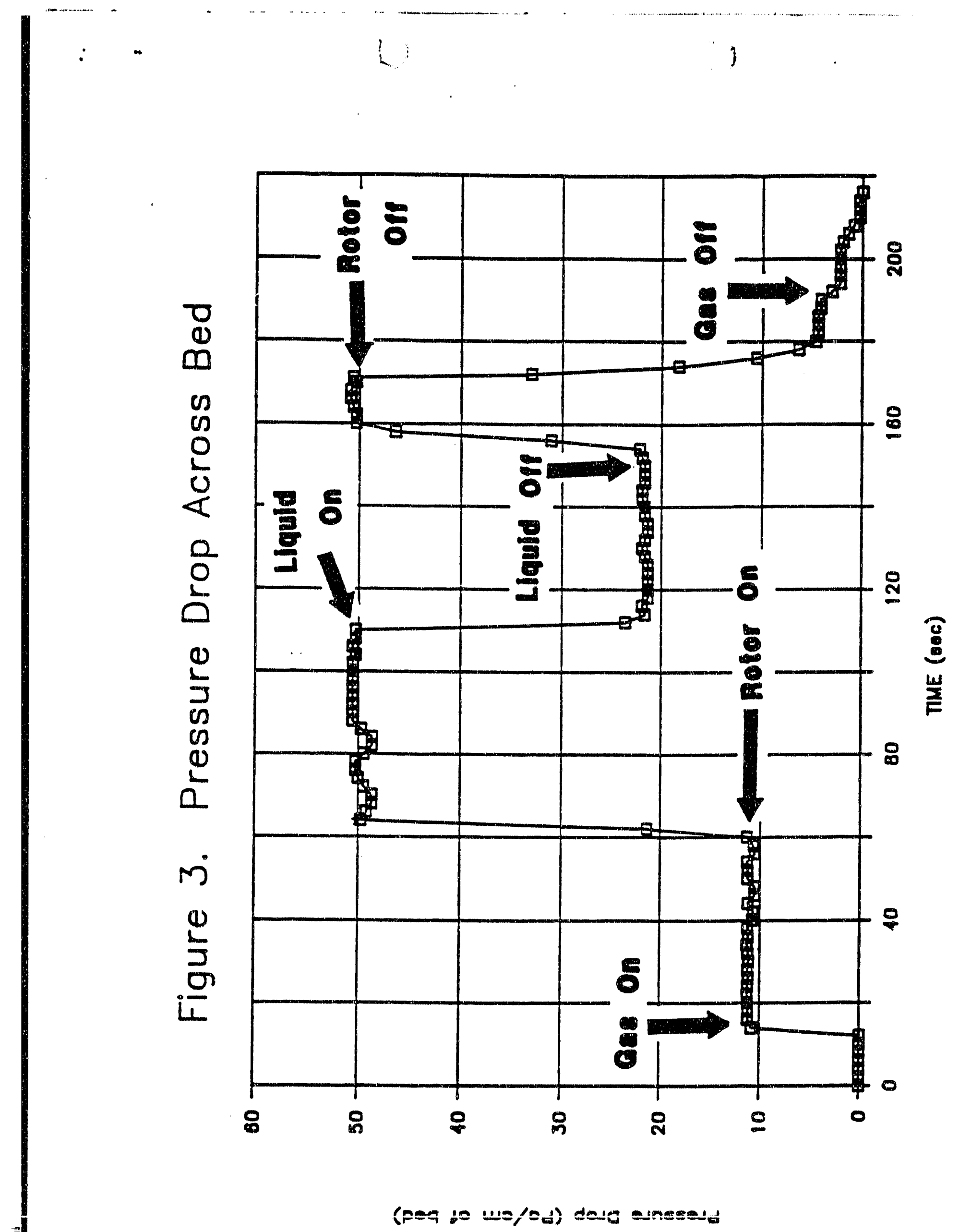
Figure 4. Pressure Drop at Varying Gravitational Fields
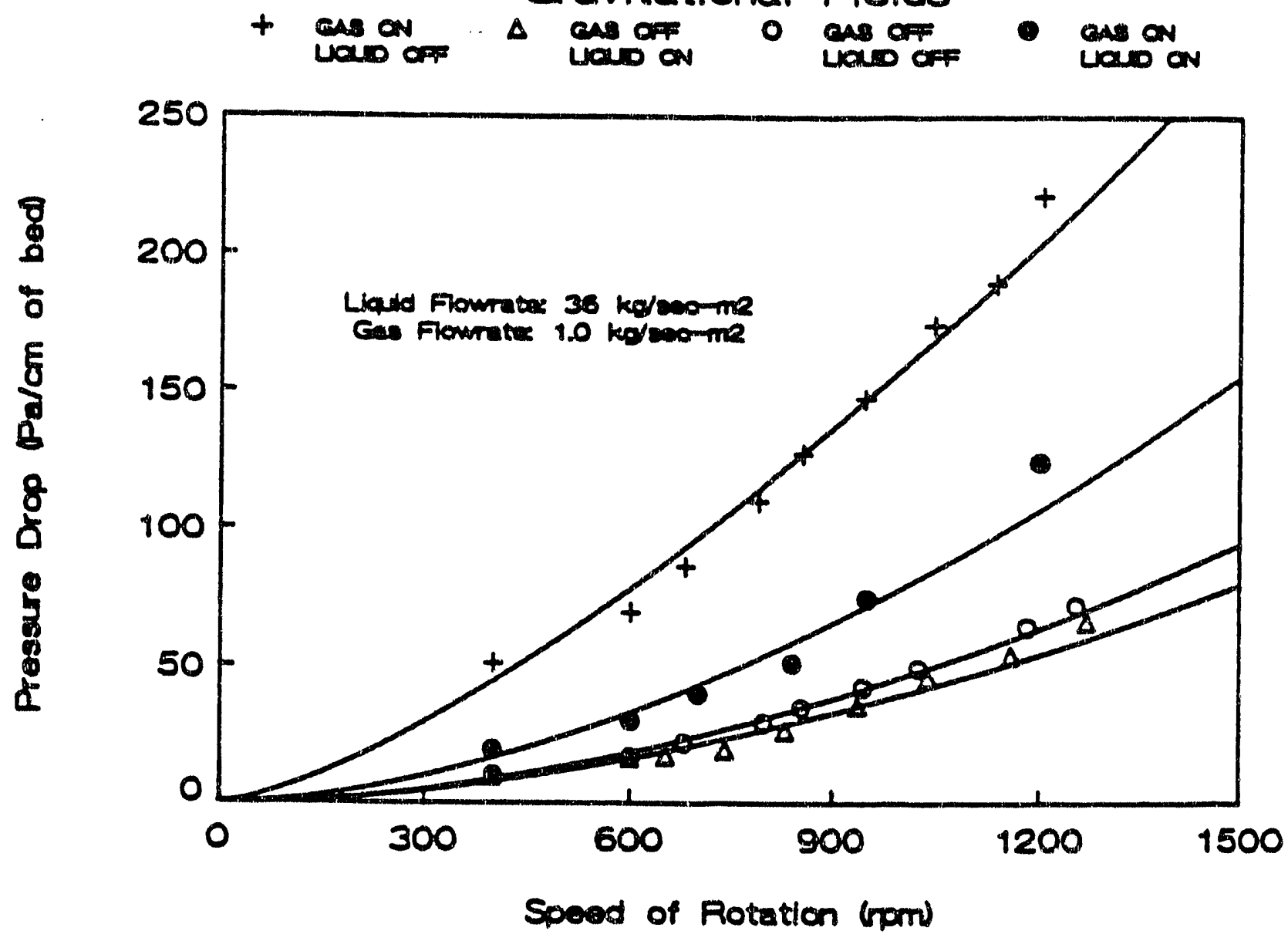
Fiare 6. Pressure Drop vs Ges Flowrate at Varying Accelerations

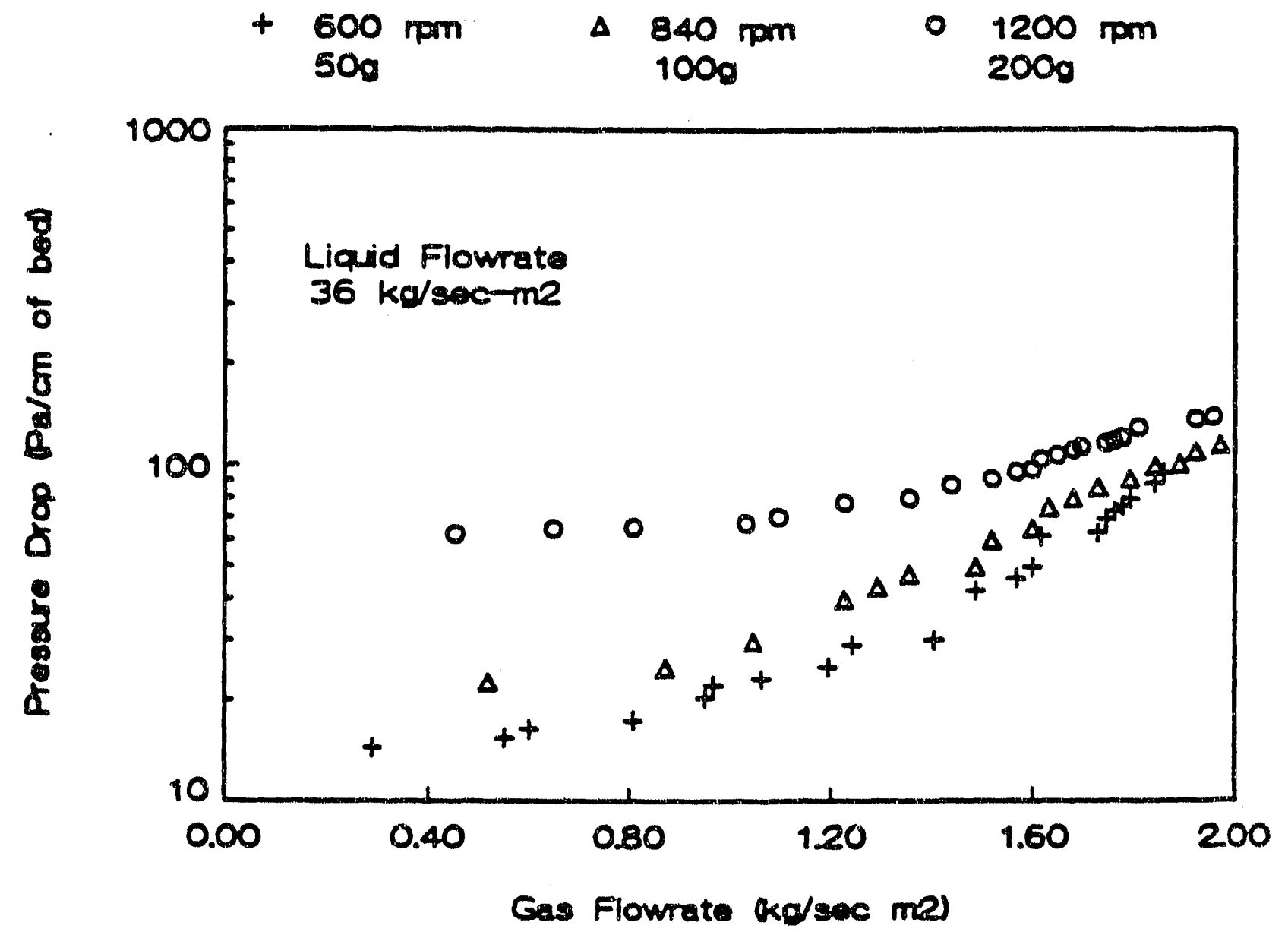


Fiare 7. Presare Drop va Liand

Flowrate at Varying Rotational Speneds

- cos rom ... $\quad 000$ rom

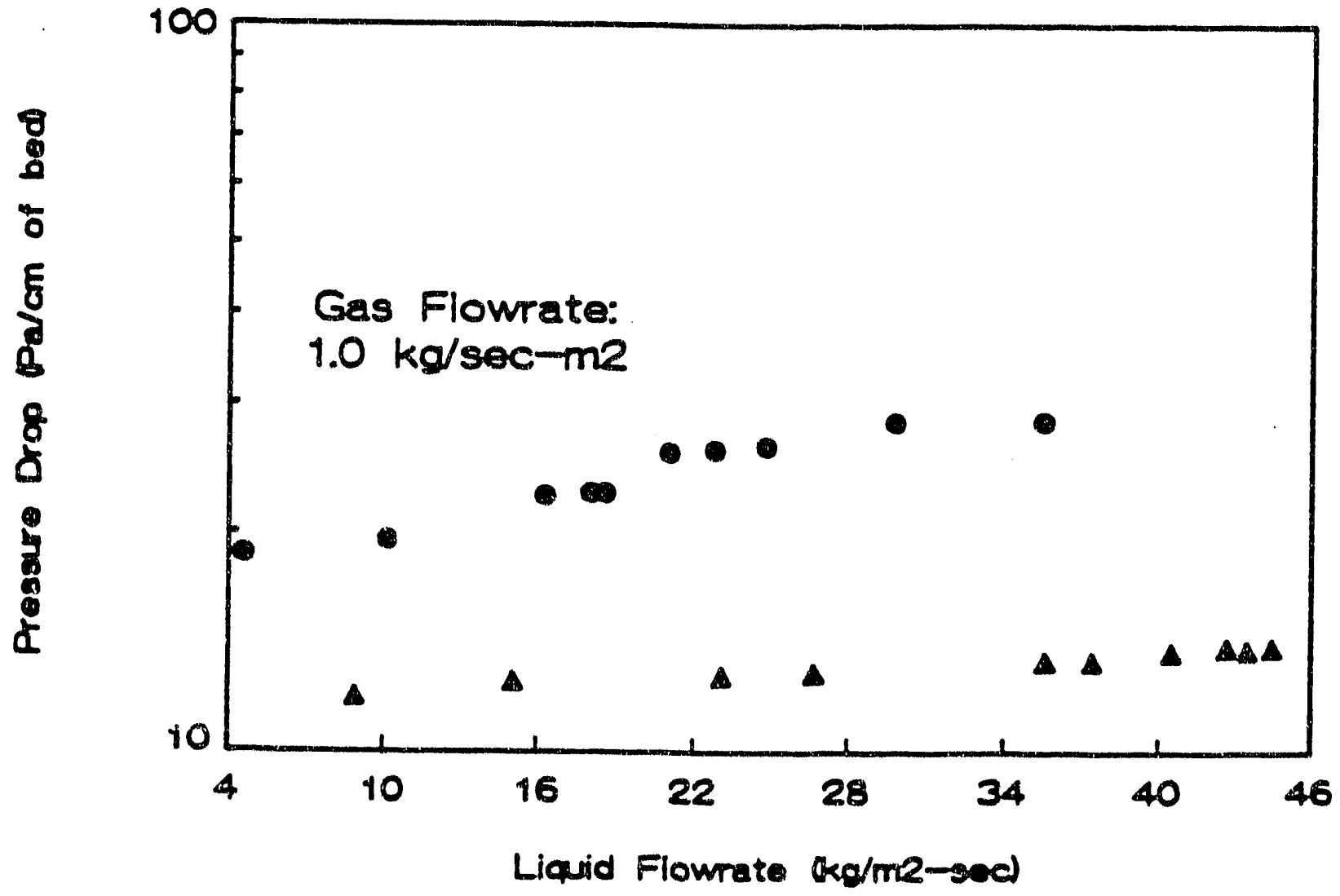


Figure 8. Pressure Drop vs. Packing Specific Surface Areas
- $600 \mathrm{rmm}$
$\triangle 900 \mathrm{rom}$
Wot Bod
Dry Bed
- $900 \mathrm{rrm}$
Wet Bod

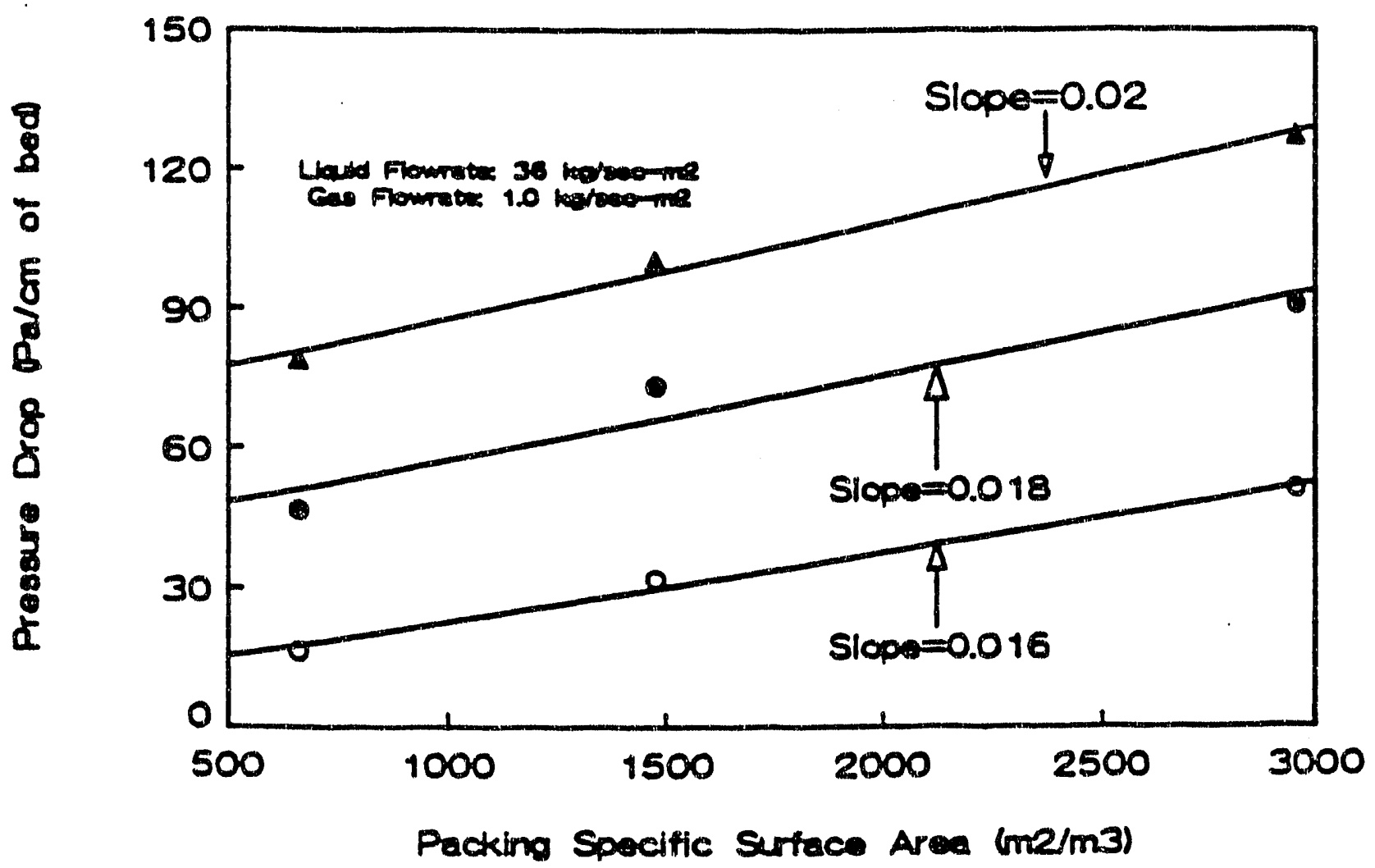


Flare 9. Comparison Betwoen Mesaured And Calalated Prosedre Drap of No Flow

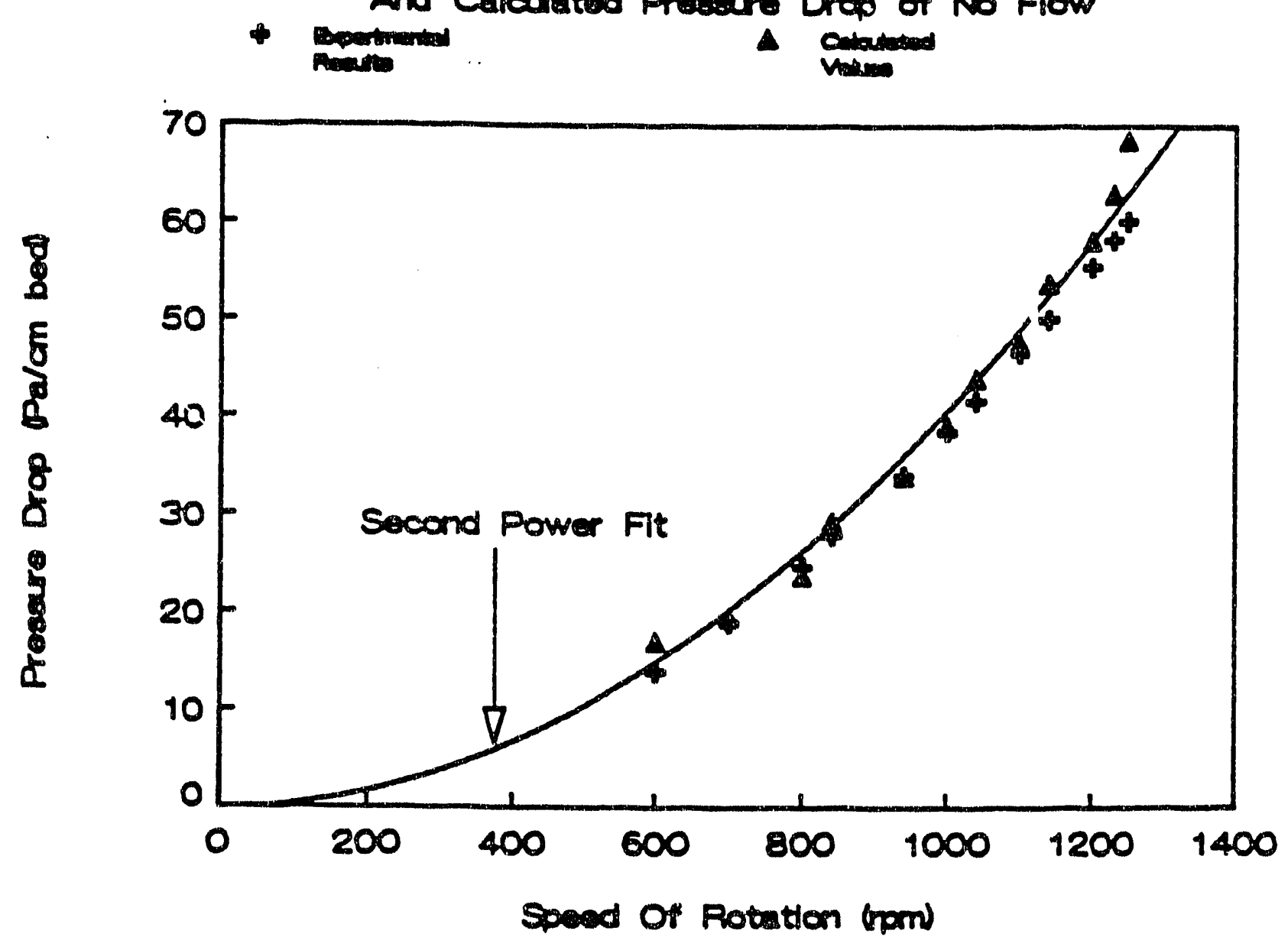




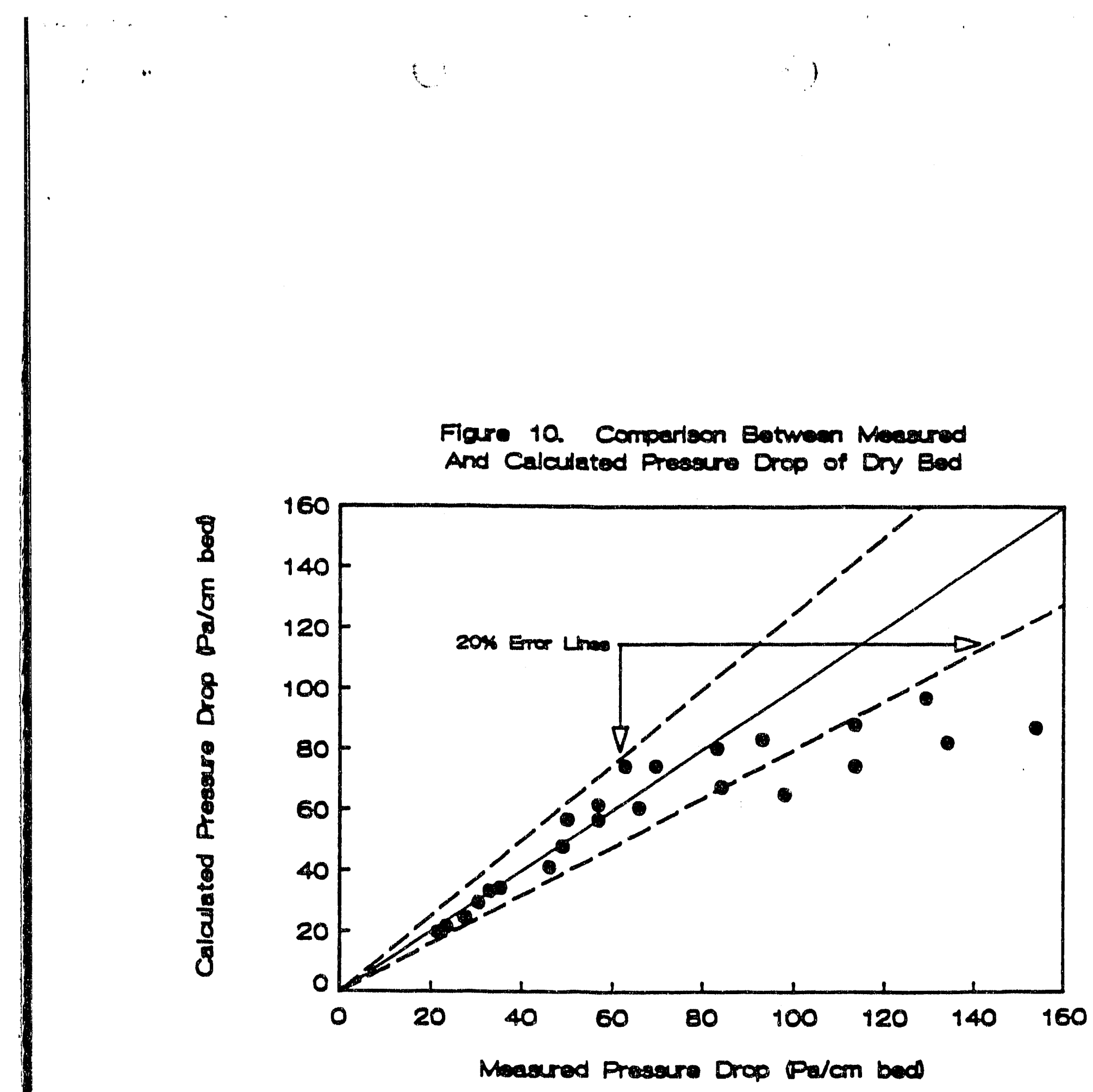


Figure 12. HTU at Varying Accelerations

- $656 \mathrm{~m} 2 / \mathrm{m}^{3} \Delta \quad 1476 \mathrm{me} / \mathrm{m}^{3}$ - $2952 \mathrm{~m} 2 / \mathrm{m}^{3}$

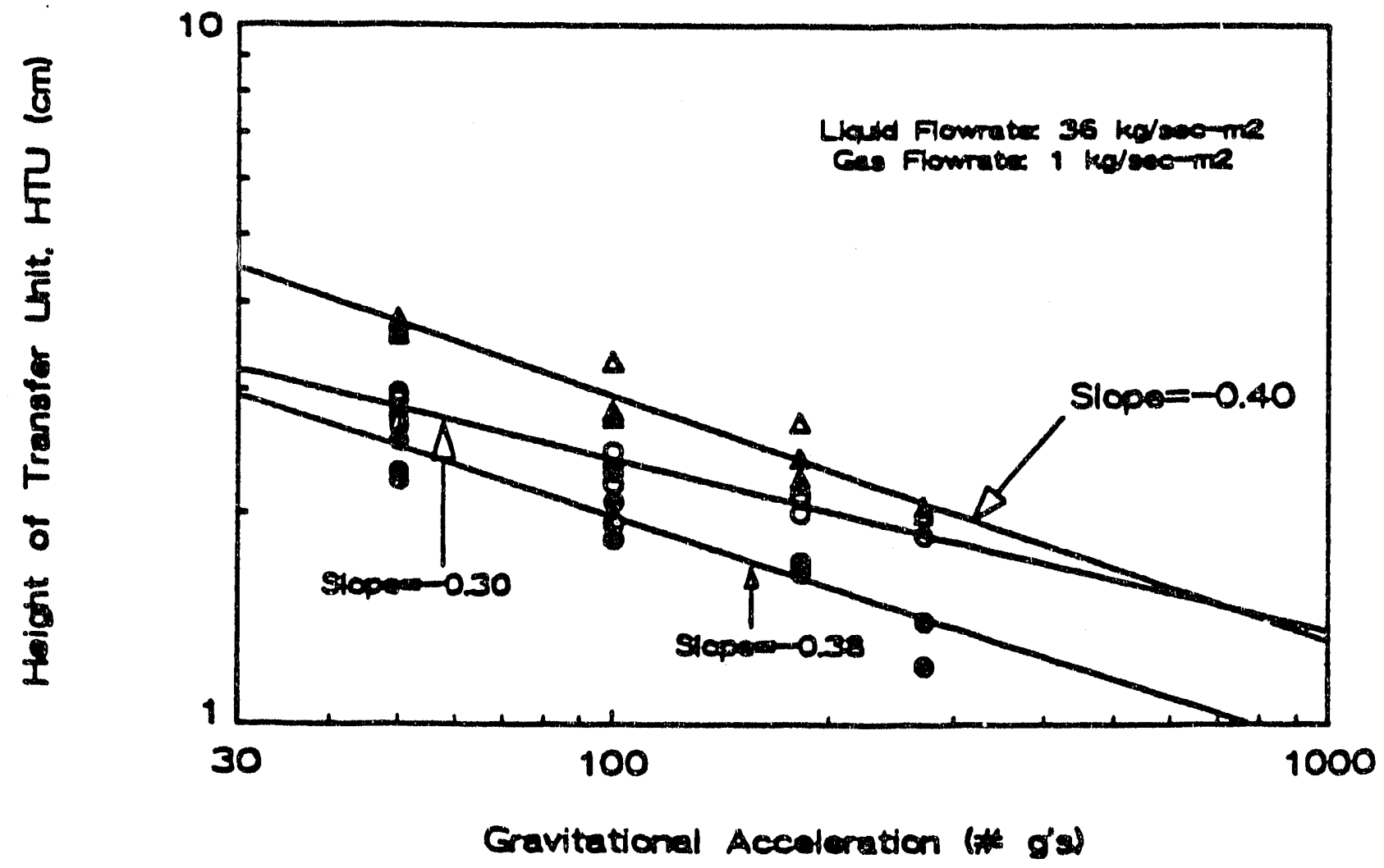


Figure 13. Variation of Volumetric Mass Transfer Coefficient with Packing Area $\Delta-\Delta 500 \quad \triangle 1000 \quad \longrightarrow 1820 \quad 02720$

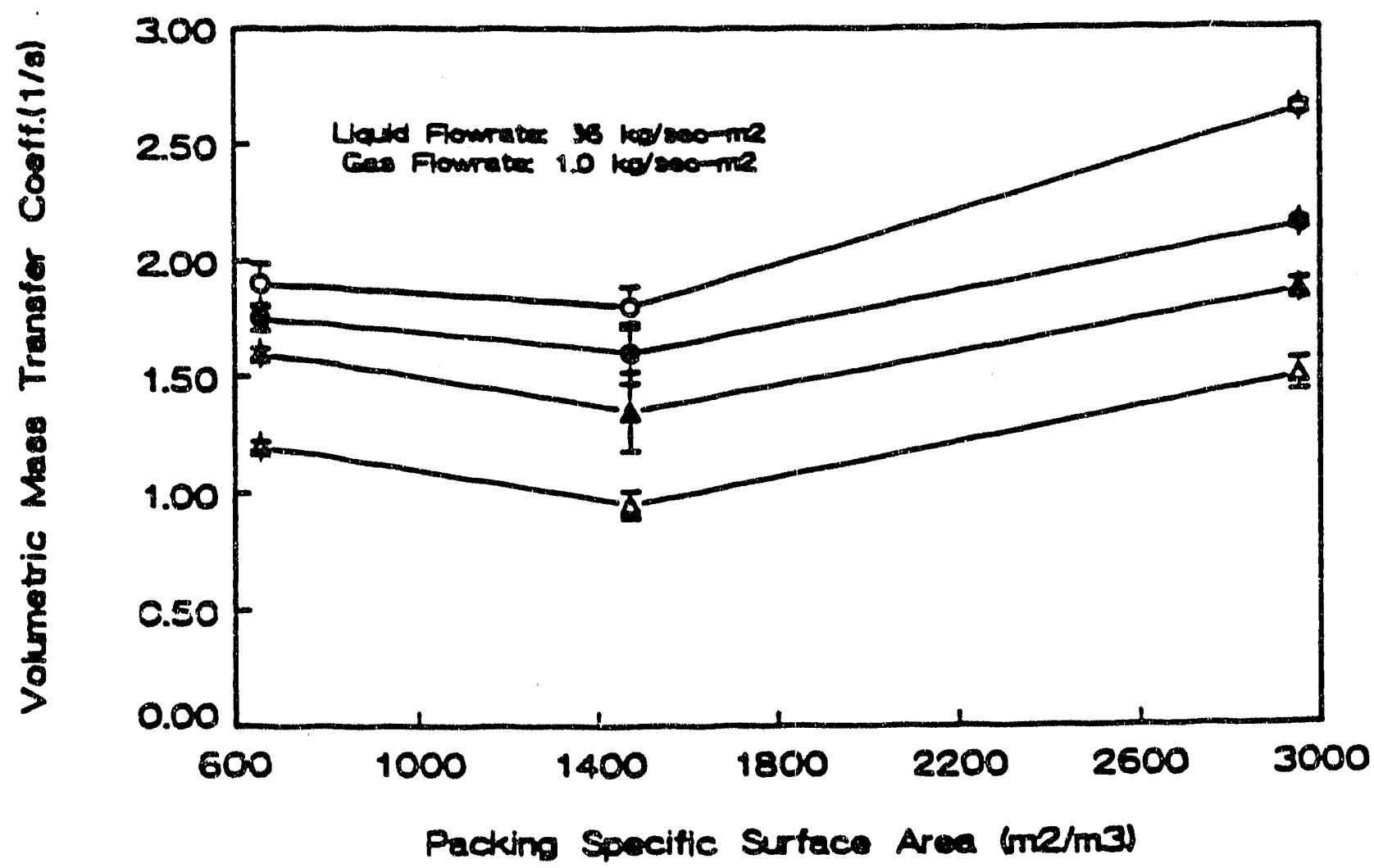


Figure 14. Comparison of Experimental and Calculated Values of HTU

$\Delta$ monosion

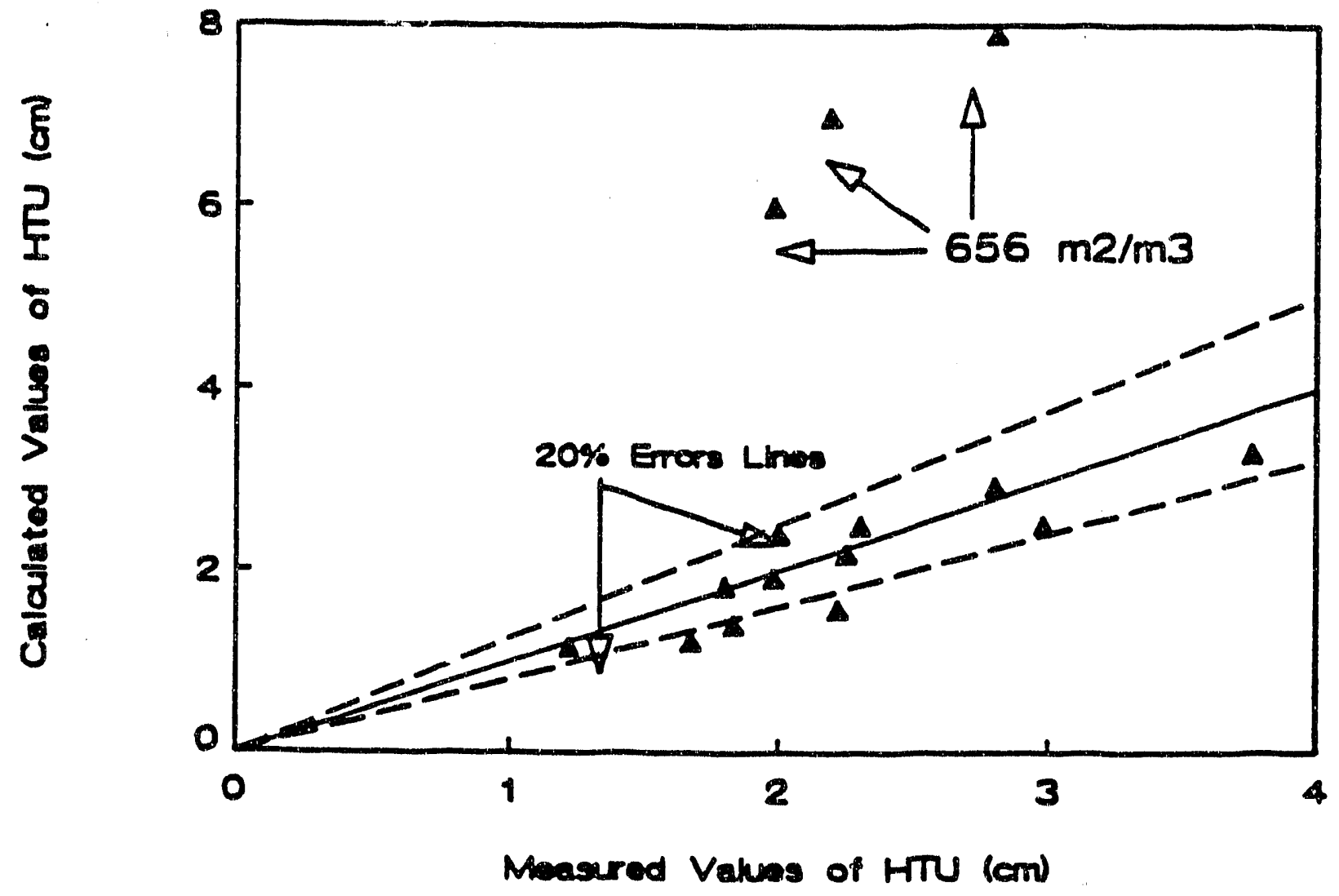


Figure 15. Total Power Consumption as Function of Liquid Flowrate + $600 \mathrm{rpm} \triangle 840 \mathrm{mpm}$ - $960 \mathrm{rpm}$

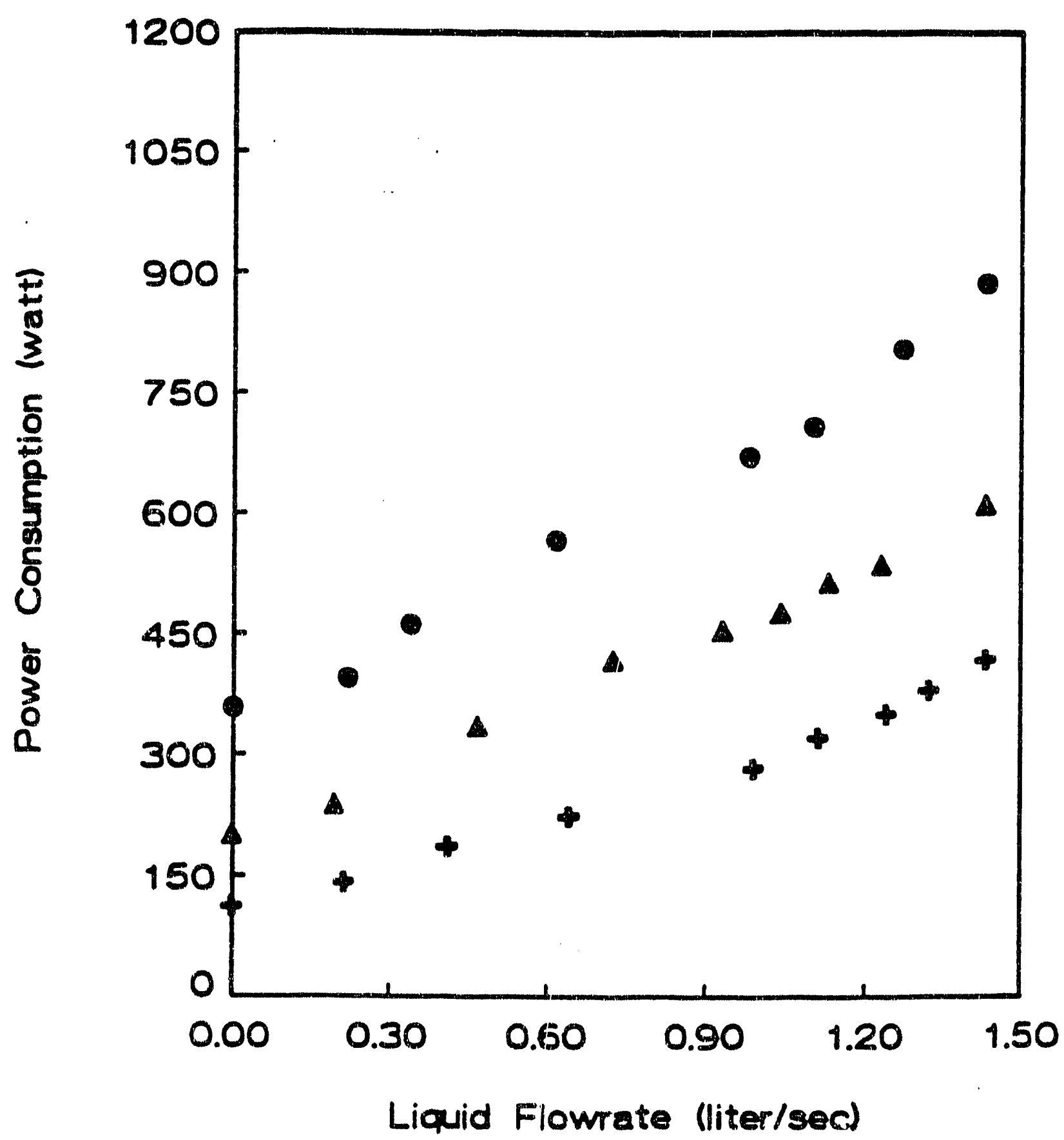


Figure 16. Windage and Bearing Power Consumption vs. Rotational Speed

$\Delta$ Bearing

Effect
- Windage

Effect

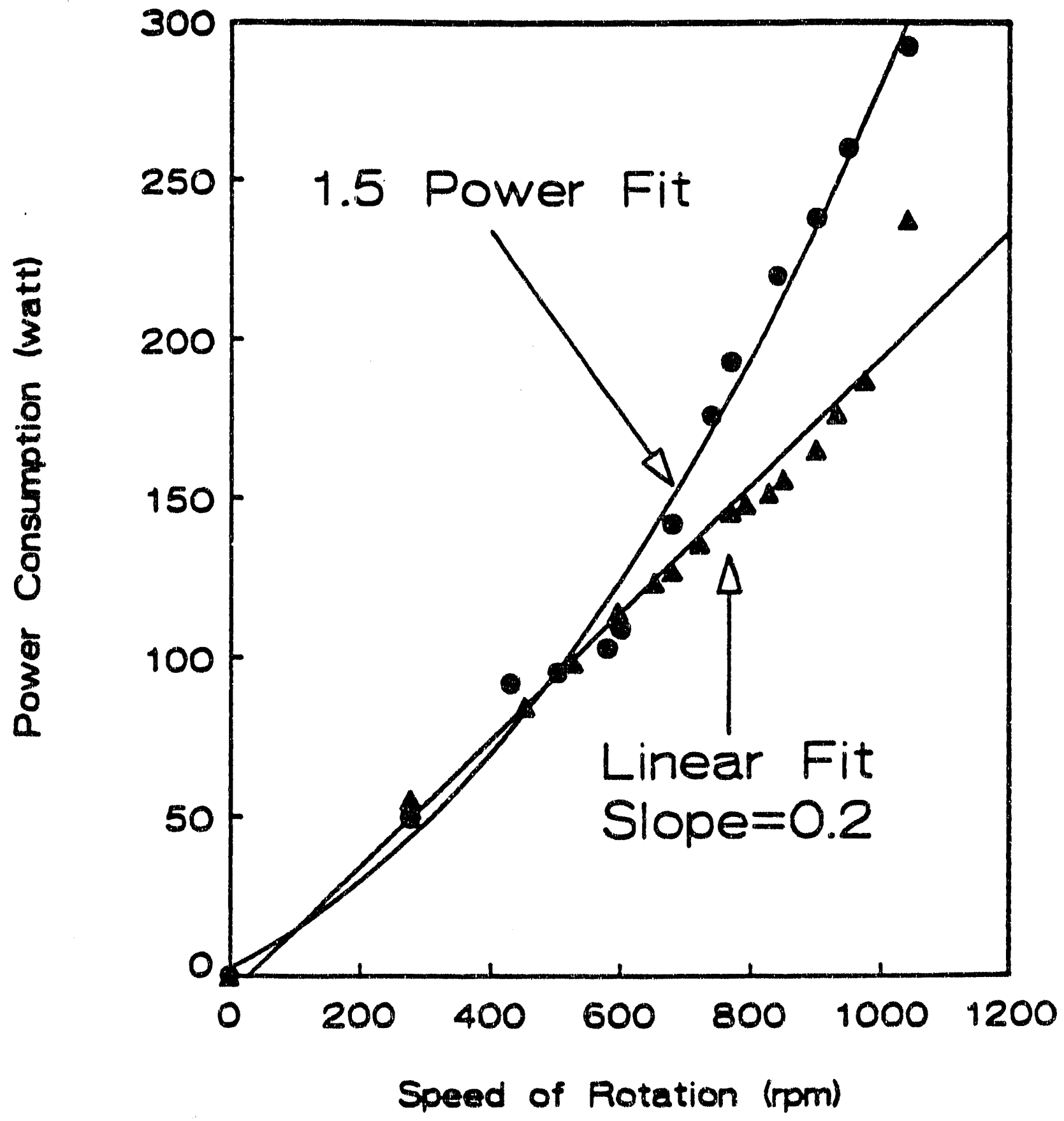


Figure 17. Power Consumption for Liquid Acceleration vs. Rotational Speed $+1.4 \mathrm{lit} / \mathrm{s} \Delta 1.0 \mathrm{lit} / \mathrm{s} \quad 0.6 \mathrm{lit} / \mathrm{s}$

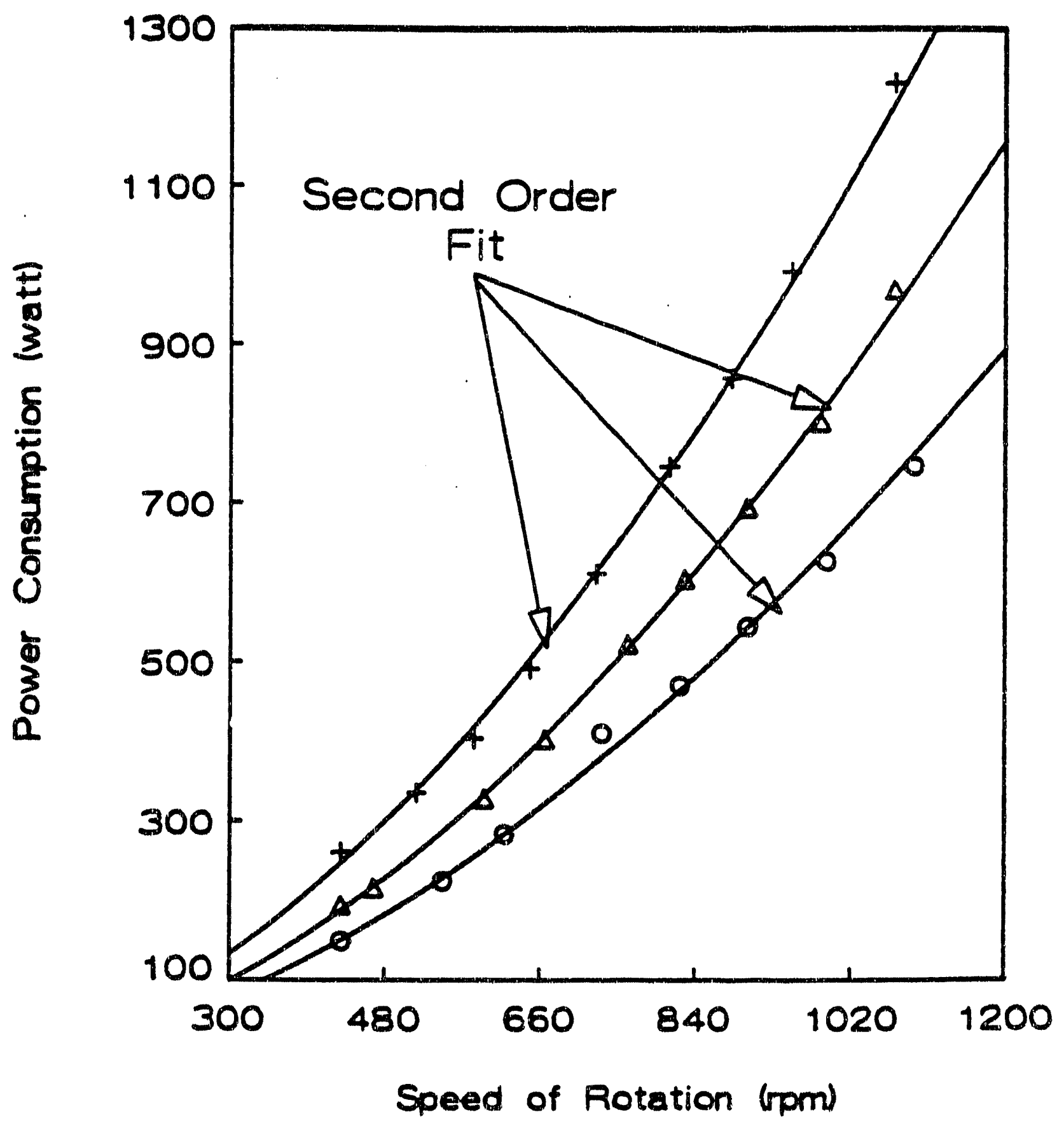


Figure 18. Comparison of Relative Values of Power Consumption Contributors

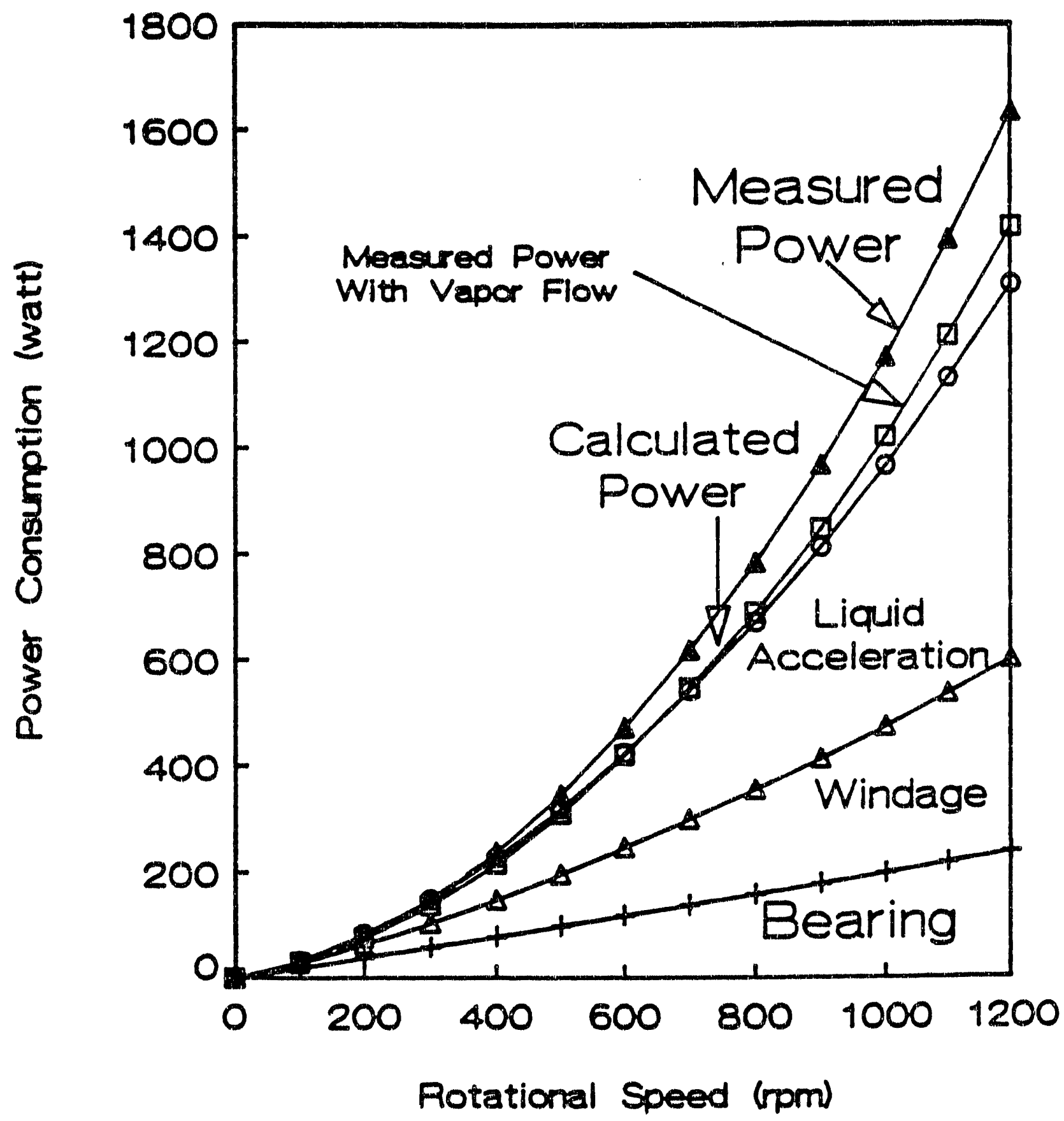




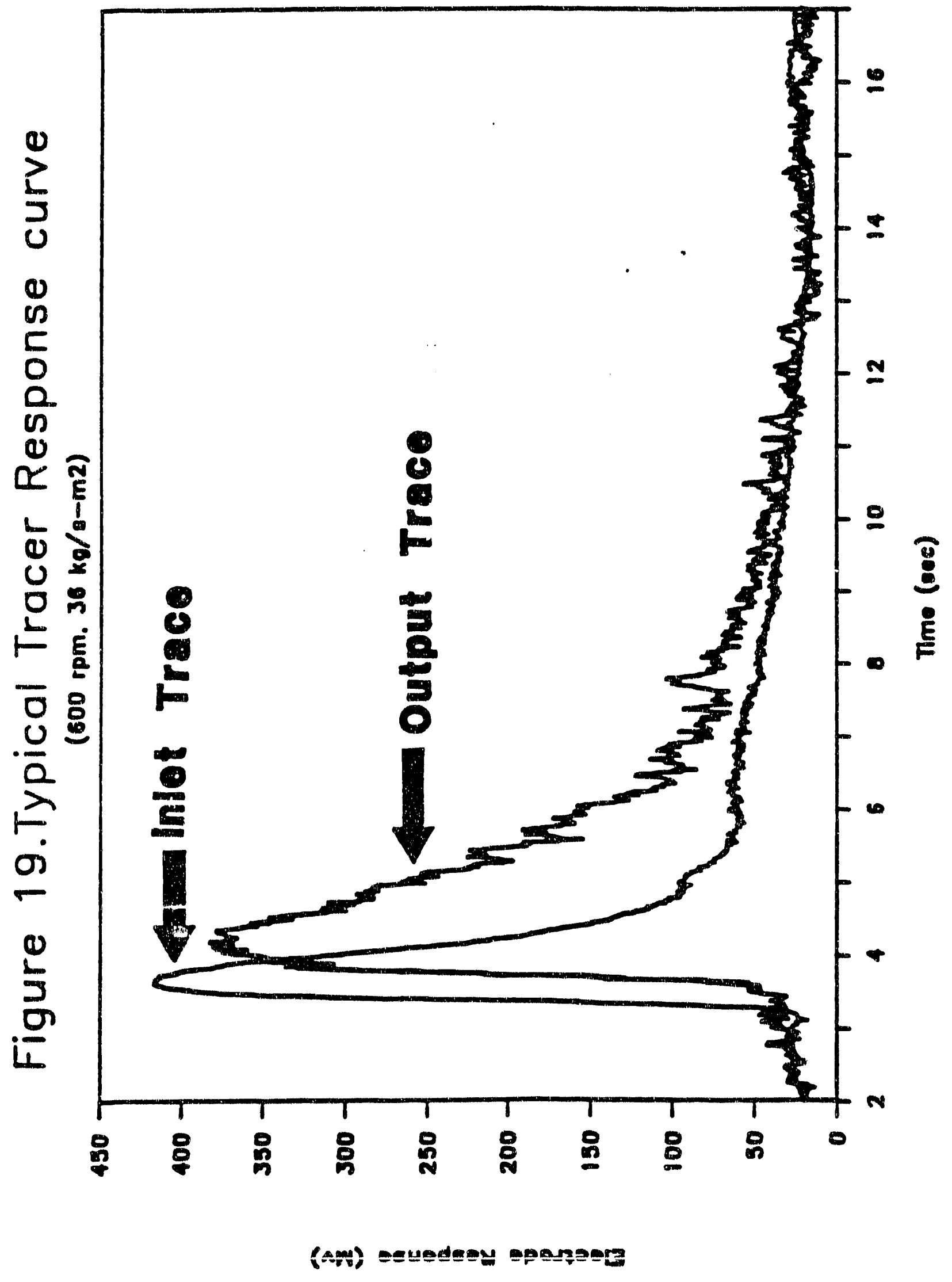


Figure 20. Effect of Rotational Speed on Mean Residence Time

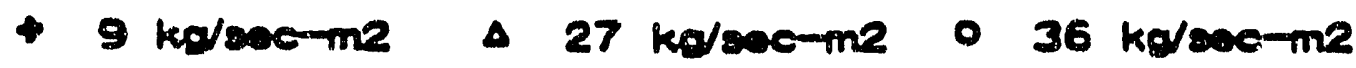

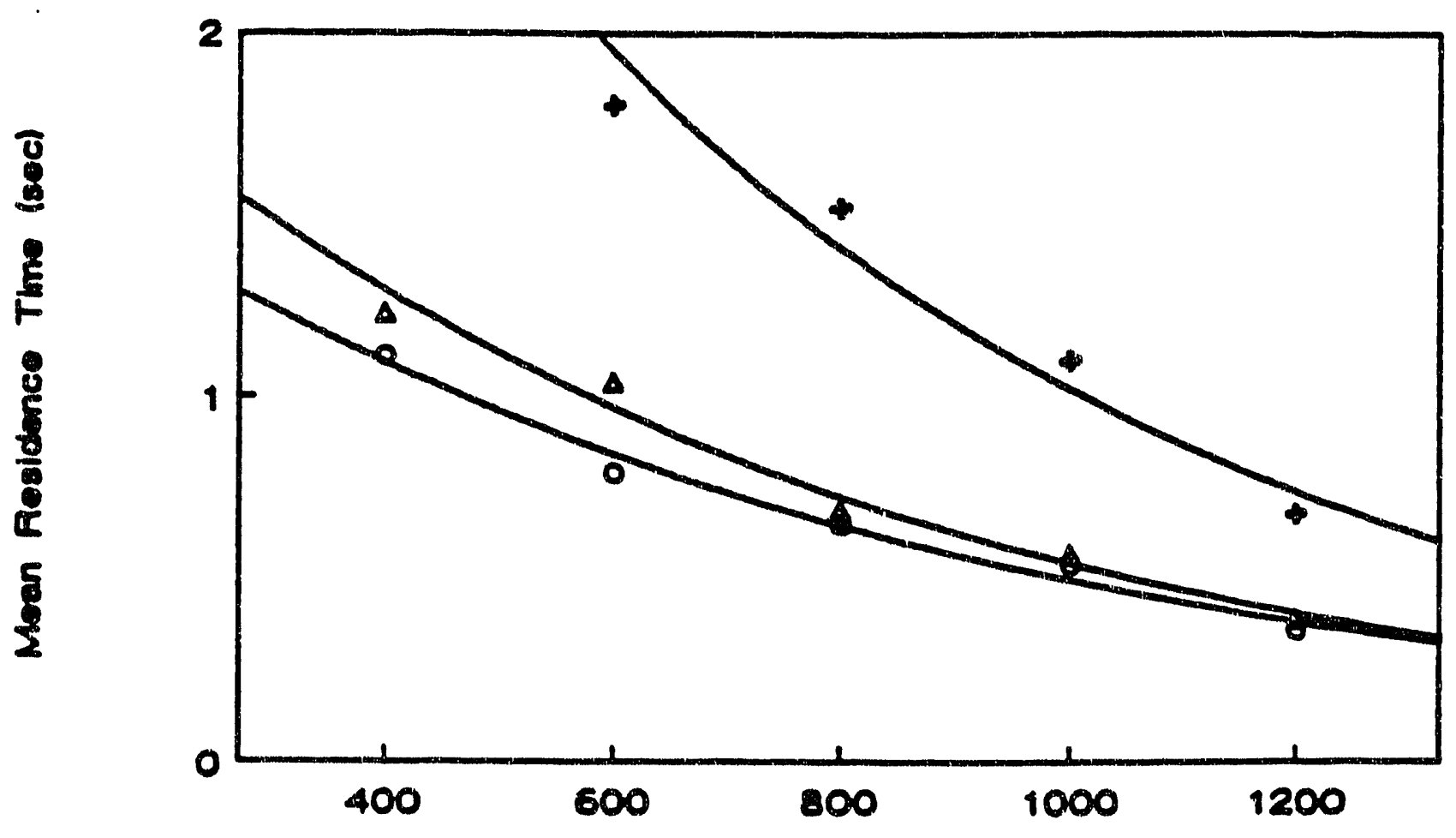

Fotational Spoed Homl 
Figure 21. Effect of Liquid Flowrate on Mean Residence Time

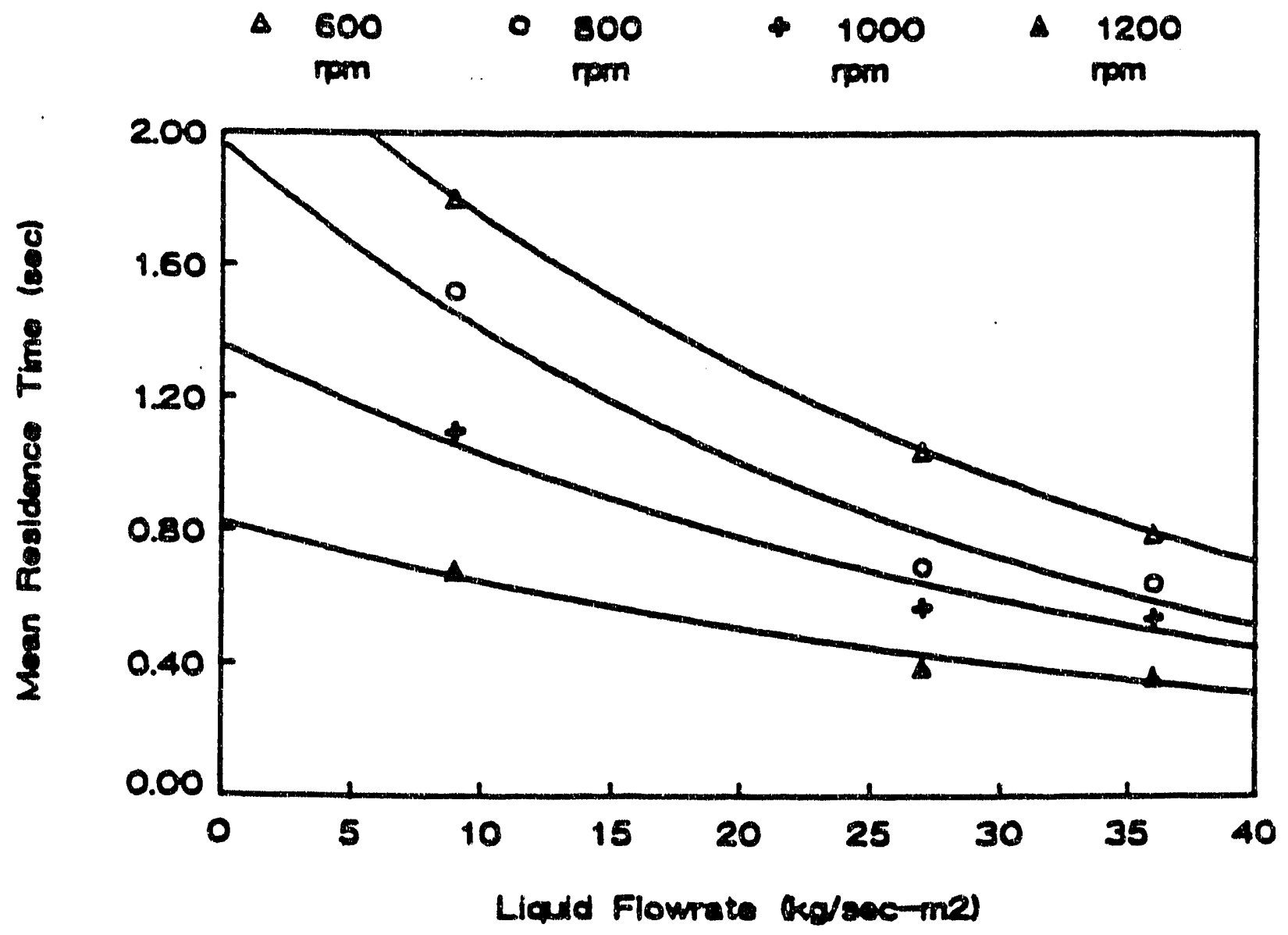




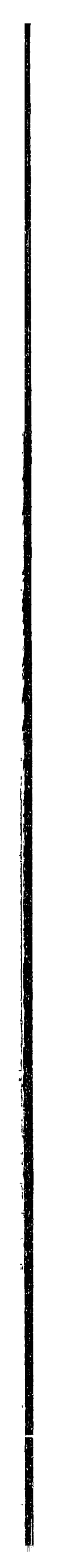

